Chemical Technology Division

\title{
DEMONSTRATION OF MERCURY SORBENTS TO MEET DOE CUSTOMER NEEDS
}

\author{
K. T. Klasson \\ D. T. Bostick \\ L. L. Farr \\ D. R. McTaggart \\ P. A. Taylor
}

Date Published: February 2000

\author{
Prepared by \\ OAK RIDGE NATIONAL LABORATORY \\ Oak Ridge, Tennessee 37831-6285 \\ managed by \\ LOCKHEED MARTIN ENERGY RESEARCH CORP. \\ for the \\ U.S. DEPARTMENT OF ENERGY \\ under contract DE-AC05-96OR22464
}





\section{CONTENTS}

Page

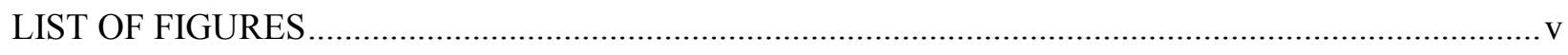

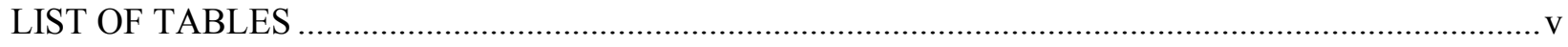

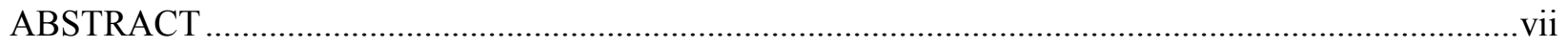

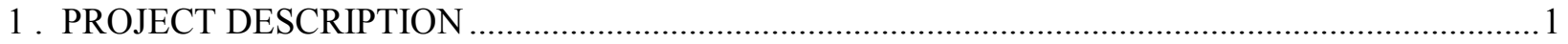

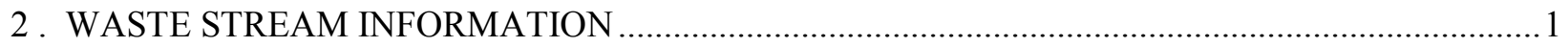

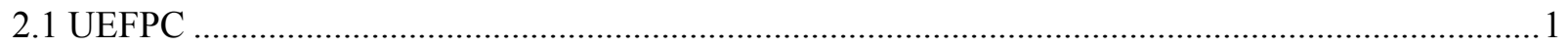

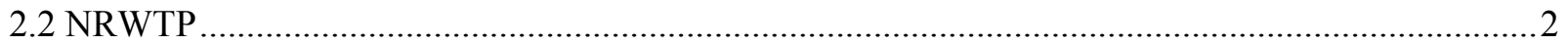

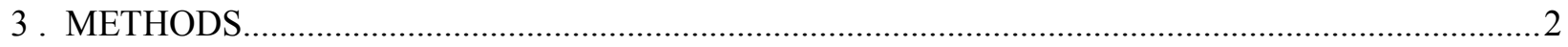

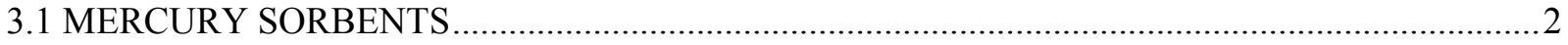

3.2 EXPERIMENTAL PROCEDURE FOR ISOTHERM EXPERIMENTS ...........................................

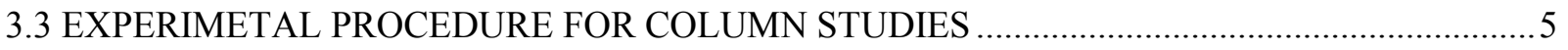

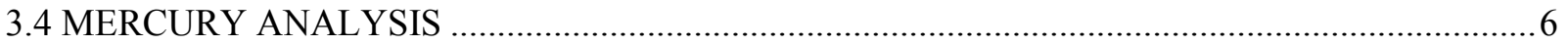

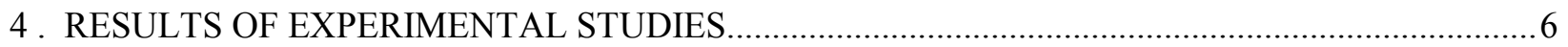

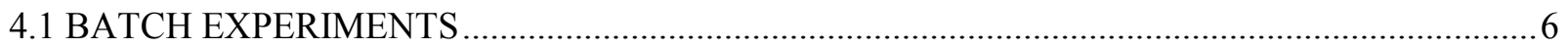

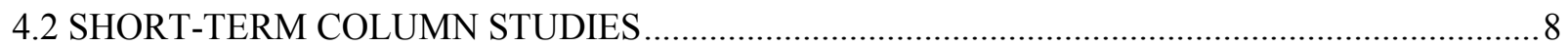

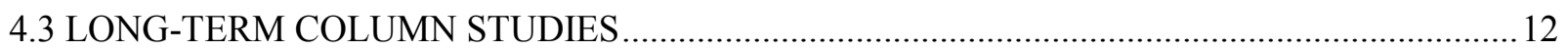

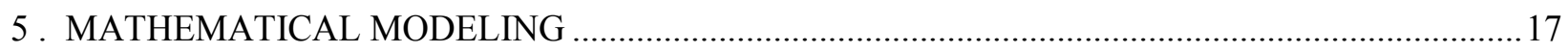

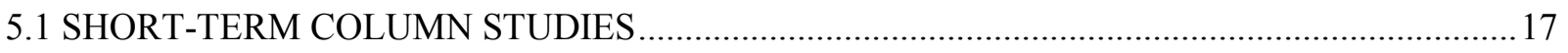

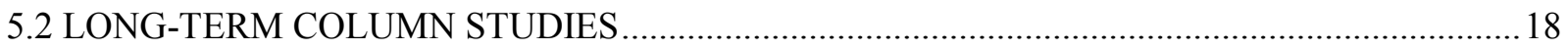

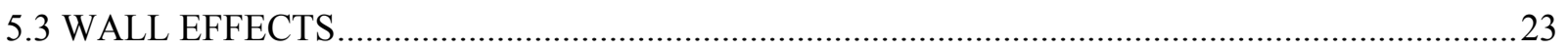

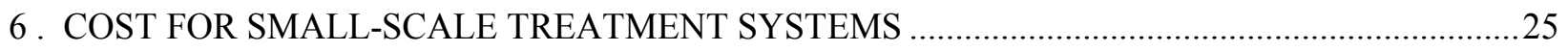

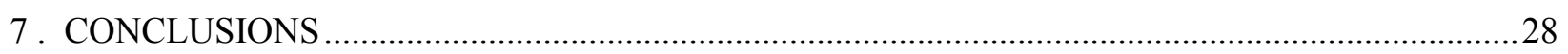

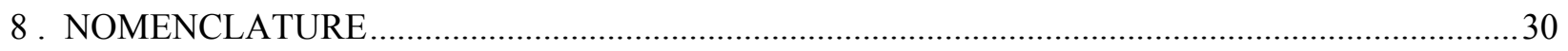

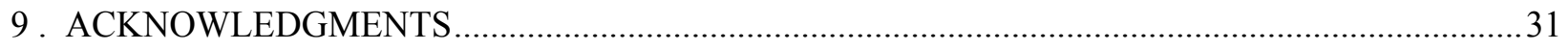

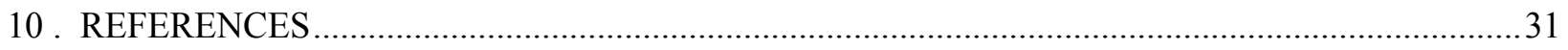

Appendix: DETAILS OF RESULTS FROM BATCH EXPERIMENTS ……........................................37 



\section{LIST OF FIGURES}

Figure $\quad \underline{\text { Page }}$

1 Photograph of the system installed at the NRWTP at ORNL .......................................................

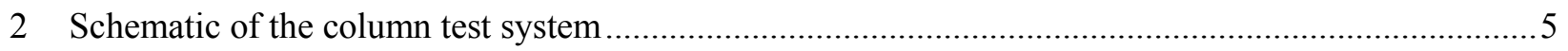

3 Isotherm results from multiweight testing of SIR-200 by ResinTech, Inc ....................................... 7

4 Results of the first set of short-term column studies at the UEFPC …..........................................

5 Results of the second set of short-term column studies at the UEFPC .............................................9

6 Results of unfiltered and filtered samples collected during the short-term column studies conducted at

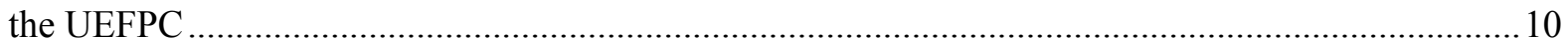

7 Summary of the filtration data collected from short-term column studies conducted at the UEFPC...11

8 Results of an NRWTP filtration study of water entering the small-scale treatment system................ 12

9 Effluent concentrations from the columns used in the long-term study at the UEFPC .......................13

10 Effluent concentrations from the columns used in the long-term study at the NRWTP.....................13

11 Effluent concentrations from the columns used in the long-term study at the UEFPC ..................... 14

12 Effluent concentrations from the columns used in the long-term study at the NRWTP..................... 14

13 Summary of results from filtered and unfiltered samples collected at the UEFPC at different times during the study

14 Summary of results from filtered and unfiltered samples collected at the NRWTP at different times during the study

15 Summary of the filtration data collected from long-term column studies........................................ 16

16 Mathematical modeling of hypothetical sorbents with different internal diffusivities ........................ 18

17 Prediction of profiles for short-term column studies for removal of free mercury............................... 19

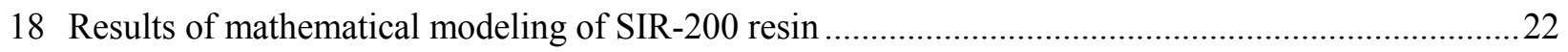

19 Cross section of column packed with spherical packing ..............................................................23

20 Predicting wall effects during short-term column studies for the Mersorb 1.5-mm sorbent ...............25

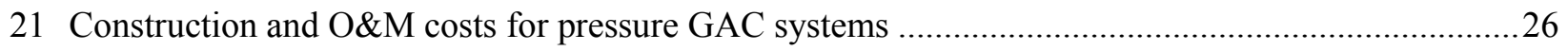

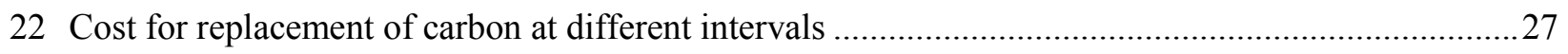

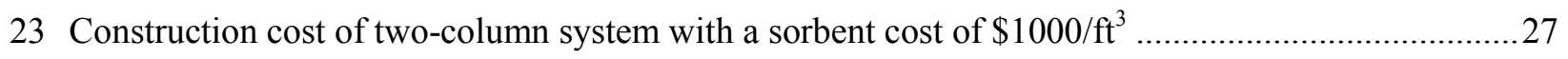

24 Construction cost as a function of processing flow rate and sorbent cost .......................................28

\section{LIST OF TABLES}

Table $\quad \underline{\text { Page }}$

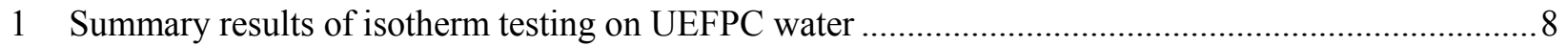

2 Parameters for modeling column performance.........................................................................22 



\begin{abstract}
Many sorbents have been developed for the removal of mercury and heavy metals from water; however, the majority of data published to date do not address the removal of mercury to the target levels represented in this project. The application for which these sorbents were targeted for use was the removal of mercury from microgram-per-liter levels to low nanogram-per-liter levels.
\end{abstract}

Overall, the thiol-based resins had the best performance when removing low concentrations of mercury in water at two U.S. Department of Energy facilities in field experiments. It was difficult to achieve the targeted low nanogram-per-liter levels at both sites; however, a substantial amount of mercury was removed by the resins. This is attributed to the mercury speciation, since filtration tests have shown that a significant portion of the mercury at each test location is particle bound or associated with particulate and colloidal matter.

The engineered Self-Assembled Mercaptan on Mesoporous Silica (SAMMS) material proved to be as effective as some of the commercial sorbents in removing mercury at the Nonradiological Wastewater Treatment Plant (NRWTP) at Oak Ridge National Laboratory. The material performed almost as well as some of the best sorbents at the Upper East Fork Poplar Creek site at the Oak Ridge Y-12 Plant. The most effective sorbents were SAMMS; Keyle:X, by SolmeteX, Inc.; and SIR-200, by ResinTech, Inc. It was also found that the Keyle:X performed better at the NRWTP when the water was pretreated with hypochlorite to oxidize some mercury species.

Because of the scattering of data, mathematical modeling was limited to predicting the behavior of active mercury. Since the field samples contained a substantial amount of particle-bound mercury, the mathematical models did not represent the field data very well. Nevertheless, it was useful to predict the performance of these sorbents at very low concentrations of mercury. Mathematical modeling was also used to investigate the possible wall effects in the small-scale studies. Based on a theoretical derivation of relationships, supported by the field data, it was concluded that wall effects played a very minor role in the experiments. The most important factor that governed the performance of the sorbents at high flow rates was the diffusion of mercury inside the sorbent. It was found that the values for the effective diffusivities were quite high, possibly due to blockage of macropores by the particulates.

Estimation of construction costs for treatment system indicated that the specialized sorbents would have to operate at flow rates 3 to 6 times higher than that of a comparable granular activated carbon (GAC) 
system in order to have the same construction cost. The sorptive capacity of the specialized sorbents would need to be substantially higher than that of the GAC. 


\section{PROJECT DESCRIPTION}

Researchers in the Chemical Technology Division at Oak Ridge National Laboratory (ORNL) have engaged in several activities related to field and laboratory testing of sorbents and chelators for removal of mercury from water.

The objective of this study was to compare a sorbent developed by the U.S. Department of Energy (DOE) with commercially (or near commercially) available ion-exchange or sorption resins. The scope of the study included small-scale batch testing, short-term kinetic studies, and long-term studies at two field sites.

\section{WASTE STREAM INFORMATION}

Two sites at DOE Oak Ridge facilities have large-volume water streams with low concentrations of mercury. The Nonradiological Wastewater Treatment Plant (NRWTP) at ORNL is operated by waste management staff, and the Upper East Fork Poplar Creek (UEFPC) Characterization Area at the Oak Ridge Y-12 Plant is managed by environmental restoration personnel. Both of these streams are regulated by National Pollutant Discharge Elimination System (NPDES) permits from the state of Tennessee. The flows are large - $350 \mathrm{gal} / \mathrm{min}(1324 \mathrm{~L} / \mathrm{min})$ at the NRWTP and $1700 \mathrm{gal} / \mathrm{min}(6434 \mathrm{~L} / \mathrm{min})$ at the UEFPC - and contain low levels of mercury in the range of 50 to $1000 \mathrm{ng} / \mathrm{L}$. The desired treatment goal is 12 to $51 \mathrm{ng} / \mathrm{L}$.

\subsection{UEFPC}

The UEFPC receives water from various sources, some of which have already received limited mercury treatment. The field testing at the Y-12 Plant was conducted on the bank of the creek at a location known as Outfall 200. The decision to test at this location was made after discussions with environmental restoration staff at the Y-12 Plant. The treatment standard for the water at this site is under negotiation with the state of Tennessee, and current estimates indicate that it may be in the range of 12 to $51 \mathrm{ng} / \mathrm{L}$. Analytical data from 1993 and 1997 indicate that five radionuclides are present in the UEFPC water at very low levels: ${ }^{234} \mathrm{Th},{ }^{230} \mathrm{Th},{ }^{238} \mathrm{U},{ }^{234} \mathrm{U}$, and ${ }^{3} \mathrm{H} .{ }^{1}$ No radiological permit was required for handling of the creek water. Other ions present in the water include $35 \mathrm{mg} / \mathrm{L}$ sulfate, $9 \mathrm{mg} / \mathrm{L} \mathrm{Na}, 10 \mathrm{mg} / \mathrm{L} \mathrm{Mg}, 2 \mathrm{mg} / \mathrm{L} \mathrm{K}$, $50 \mathrm{mg} / \mathrm{L} \mathrm{Ca}$, and $7 \mathrm{mg} / \mathrm{L} \mathrm{N}$ (in nitrate/nitrite). The $\mathrm{pH}$ is approximately 8.1 . 


\subsection{NRWTP}

The limit for mercury in the effluent from the NRWTP at ORNL was reduced to $19 \mathrm{ng} / \mathrm{L}$ (monthly average) by a 1997 NPDES permit. This value is well below the current effluent concentration. Because this new mercury limit is being appealed, it is not currently being enforced. However, experimental work was performed to determine the feasibility of meeting such a limit. The NRWTP flowsheet includes filtration using dual-media columns, an air stripper, and granular activated carbon (GAC) columns. The activated carbon columns at the NRWTP provide most of the mercury removal. The water flow rate at the NRWTP is typically $350 \mathrm{gal} / \mathrm{min}(1324 \mathrm{~L} / \mathrm{min})$. The mercury concentration before treatment by the GAC columns is about $200 \mathrm{ng} / \mathrm{L}$, but this concentration fluctuates widely. The $\mathrm{pH}$ of the stream is approximately 8 .

\section{METHODS}

\subsection{MERCURY SORBENTS}

Many sorbents have been developed for the removal of mercury and heavy metals from waters; however, the majority of data published to date do not address the removal of mercury to the target levels represented in this project. The application for which these sorbents are targeted for use is in the removal of mercury from microgram-per-liter levels to low nanogram-per-liter levels. As part of this work, the availability of sorbents designed for removal of mercury from water was surveyed. Sorbents with thiouronium, thiol, amine, sulfur, and proprietary functional groups were selected for these studies.

Several commercial macroporous polystyrene/divinylbenzene resins with (iso)thiouronium functional groups are available for mercury adsorption. These types of sorbents have been found by Sybron Chemicals, Inc., to bind ionic mercury(II), methyl mercury, and elemental mercury, but the solvents cannot be regenerated. They perform best at $\mathrm{pH}$ values between 0 and 6 . At higher $\mathrm{pH}$ levels, the thiouronium group is converted to a thiol group. Examples of such sorbents are Ionac SR-3 (Sybron Chemicals, Inc.), SIR-400 (ResinTech, Inc.), and Purolite S-920 (Purolite Company).

Cation resins with thiol functional groups are also commercially available for mercury adsorption. The sorbents can be used at $\mathrm{pH}$ values ranging from 1 to 14 . Materials with this type of functionality are macroporous, weakly acidic polystyrene/divinylbenzene resins such as Duolite GT-73 (Rohm and Haas), Ionac SR-4, and SIR-200. Self-Assembled Mercaptan on Mesoporous Silica (SAMMS) is a new inorganic thiol resin developed by Pacific Northwest National Laboratory (PNNL). PNNL has presented 
data indicating that elemental and organic mercury may be adsorbed by SAMMS. ${ }^{2}$ In general, the thiol resins can sorb only mercury(II) ions. The SAMMS material (a fine powder) was incorporated by ORNL into hydrous zirconium oxide microspheres, which were embedded with approximately $40 \%$ SAAMS (dry weight). The microspheres were air dried to a constant weight.

Keyle:X is a polyacrylate resin coated with a proprietary polymer with sulfur-based functional groups, making it mercury specific. The manufacturer recommends that the water be pretreated with chlorine, hypochlorite, or chlorine dioxide to $1-2 \mathrm{mg} / \mathrm{L}$ to ensure that the mercury is in the ionic state.

Manufacturers of polystyrene/divinylbenzene resin specifically recommend removing such oxidizers prior to contact.

Amberlite IRC-718, manufactured by Rohm and Haas, is a resin with an iminodiacetate functional group that is selective for heavy metals. A similar resin, SR-5, is available from Sybron Chemicals. This resin can be used over a pH range of 1.5 to 14 and binds ionic forms of mercury. However, Rohm and Haas personnel have recommended that IRC-718 not be used for removing low levels of mercury in water. They suggest thiol resins as the alternative. For this reason, iminodiacetate functional group resins were excluded from the tests.

ChelaTech, Inc., manufactures a high-performance extraction media, which contains organic ligands (containing amine and thiol groups) attached to a silica support. The particle size is small, 100-250 $\mu \mathrm{m}$, and the normal operating back-pressure is 50-100 psig. Operation at flow rates up to 40 bed volumes $(\mathrm{BV}) / \mathrm{min}$ is possible. Because of the anticipated high pressure drop in a full-scale system, this sorbent was not selected for the studies. A similar resin construction (e.g., Superlig 608 and Superlig 618) is available from IBC Advanced Technologies, Inc., which designs molecular recognition groups that provide highly selective nonionic-exchange organic ligands chemically bonded to silica gel. These very robust sorbents, which can be used under extreme conditions, ${ }^{3}$ bind ionic mercury(II). Superlig 618 is used in acidic environments; Superlig 608 is used in alkaline environments. These resins are not available in large volumes, and the cost is quite high $(\$ 30,000 / \mathrm{L})$. Consequently, these resins were not selected.

Mersorb LW, Mersorb 3, and Mersorb $1.5 \mathrm{~mm}$ are commercial carbons impregnated with sulfur. The only difference between the three carbons is particle size. Because the sorption is dependent on precipitation of the sulfide, competing metal ions are those that form strong sulfide bonds (e.g., $\mathrm{Cu}, \mathrm{Ag}$, $\mathrm{Cd}, \mathrm{Zn}, \mathrm{Pb}, \mathrm{Fe}$ ). Mersorb $1.5 \mathrm{~mm}$ was used in the column studies. 
Noble metal-impregnated carbon (e.g., C-E100-Alpha1Mix by ADA Technologies, Inc.) is a carbonbased sorbent infused with noble metal(s). According to the manufacturer, this sorbent can be regenerated by heating to $370^{\circ} \mathrm{C}$.

The Forager Sponge, by Dynaphore, Inc., is an open-cell cellulose sponge incorporating an aminecontaining polymer that has selectivity for both cationic and anionic species of mercury and other heavy metals. It has the advantage of being a very porous compressible sponge; thus, column capacity can easily be adjusted by altering the packing density. The sponge can be pretreated with acid or base to change functionality (anionic versus cationic).

GAC is used at the NRWTP for removal of mercury and semivolatile organics. It is also used in two mercury treatment systems located at the Y-12 Plant for treatment of streams collected from buildings. Filtrasorb 300 (Calgon Carbon Corporation) and Cecarbon GAC 30 (Atochem, Inc.) were chosen as base sorbents for comparison purposes for the UEFPC and NRWTP water, respectively.

The cost of resin-based sorbents ranges from $\$ 12$ to $\$ 70$ per liter and is dependent on the quantity purchased. The cost of granular activated carbon is approximately $\$ 3.8 / \mathrm{L}$, and the cost of Mersorb and Forager Sponge is $\$ 5 / \mathrm{L}$. Cost details for some of the noncommercial sorbents were not available for comparison purposes. Individual cost and detailed information about each sorbent has been published elsewhere. $^{4}$

\subsection{EXPERIMENTAL PROCEDURE FOR ISOTHERM EXPERIMENTS}

The batch sorption experiment was conducted with water collected from East Fork Poplar Creek at Outfall 200 at the Y-12 Plant. The water was collected after passing through a $1-\mu \mathrm{m}$ filter.

The batch isotherm samples were run in 250-mL I-Chem bottles with Teflon-lined closures. Various amounts of sorbent masses were mixed on a Labquake ${ }^{\circledR}$ shaker for $24 \mathrm{~h}$ at room temperature (22 to $24^{\circ} \mathrm{C}$ ). The aqueous phase was separated by using a filter and transferred to a clean $125-\mathrm{mL}$ I-Chem bottle prior to refrigeration, shipment, and analyses. The sample set included several quality control samples. Further details about the procedure have been previously published. ${ }^{5}$ 


\subsection{EXPERIMETAL PROCEDURE FOR COLUMN STUDIES}

The test systems, operated in the field at ORNL and the Y-12 Plant, consisted of a 1- $\mu$ m (nominal pore size) filter cartridge, a set of flow meters, and a corresponding set of columns. Each of the columns had an inside diameter of $25 \mathrm{~mm}$ and was packed with $70 \mathrm{~mL}$ of sorbent to a height of approximately $125 \mathrm{~mm}$ (Fig. 1). A schematic diagram of the test system may be found in Fig. 2. A constant-pressure water supply was available at both sites - at ORNL as a slipstream from the wastewater treatment plant (just upstream of the existing GAC columns) and at the Y-12 Plant via a submersible pump in the creek.

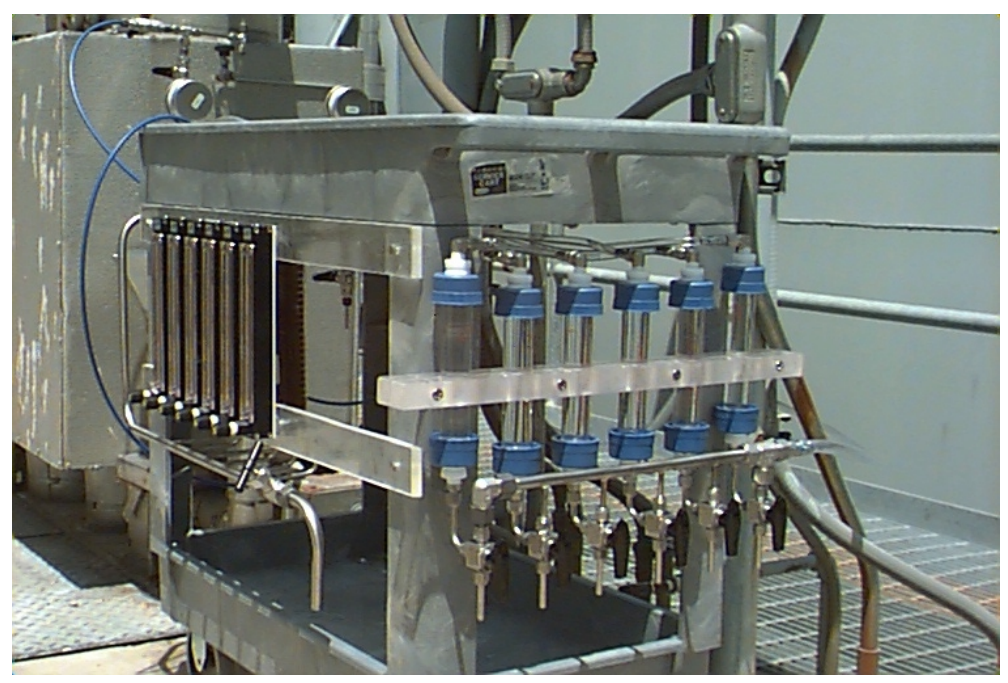

Fig. 1. Photograph of the system installed at the NRWTP at ORNL. A similar system was installed at the UEFPC at the Y-12 Plant.

Flow Meters

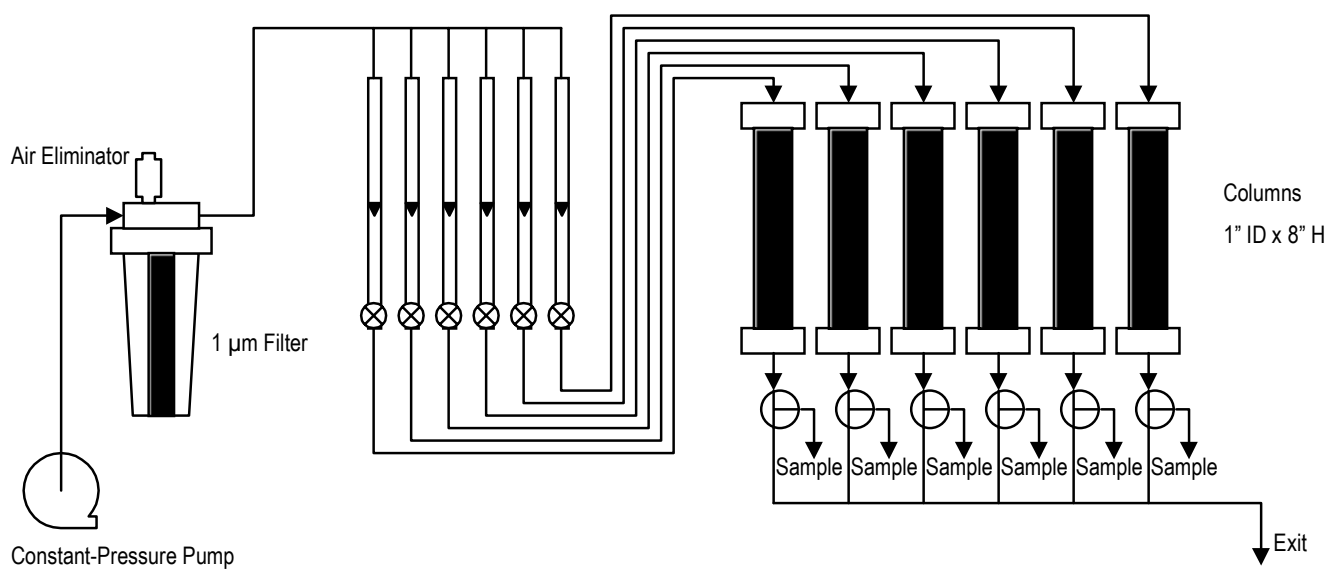

Fig. 2. Schematic of the column test system. 
Two types of studies were performed, the first of which was a short-term study at various flow rates. The experiment was started at a flow rate of about $7 \mathrm{~mL} / \mathrm{min}[0.1 \mathrm{BV} / \mathrm{min}]$. Samples were taken from each column after 20 and $24 \mathrm{~h}$ of operation, and the flow rate was then increased to a new setting. This sampling procedure was repeated, and the flow rate was again increased. After samples had been collected at the highest flow rate, the flow rate was decreased to $7 \mathrm{~mL} / \mathrm{min}$ and samples were collected again. Some of the samples were collected and filtered before mercury analysis. Further details about the short-term column studies have been previously published. ${ }^{4,6}$

The long-term studies utilized the same column setup as that described for the short-term studies, but a single flow rate was studied over an extended period of time before the rate was changed. Flow rates of 0.3 and $0.15 \mathrm{BV} / \mathrm{min}$ were studied at the NRWTP; at the UEFPC, 0.95 and $0.35 \mathrm{BV} / \mathrm{min}$ were used. One of the sorbents (Keyle:X) was tested with pretreated water. The pretreatment consisted of a 1-L mixing jar in which a hypochlorite bleach solution was introduced to achieve a total chlorine level of $1-2 \mathrm{mg} / \mathrm{L}$.

\subsection{MERCURY ANALYSIS}

Samples were collected in clean 125-mL I-Chem bottles, refrigerated, and then shipped for analysis at an off-site laboratory (Frontier Geosciences, Inc., Seattle, WA). The samples were oxidized with $\mathrm{BrCl}$; then an aliquot was analyzed by $\mathrm{SnCl}_{2}$ reduction, dual gold amalgamation, and cold vapor atomic fluorescence detection. $^{7}$ A few samples were analyzed without using the $\mathrm{BrCl}$ in order to measure the chemically active (ionic and elemental) mercury, which would be readily accessible to the sorbents. Unless noted, all samples were collected unfiltered.

\section{RESULTS OF EXPERIMENTAL STUDIES}

\subsection{BATCH EXPERIMENTS}

The sorption capacity ( $K_{D}$, equal to loading divided by equilibrium concentration) was calculated — loss of mercury was attributed primarily to sorption on equipment walls. A sorption ratio for the "walls" was calculated by assuming that the initial mercury concentration, $[\mathrm{Hg}]_{9}$, was represented by the untreated stream sample (see Appendix, sample 9) that was immediately refrigerated (plus any spike). The final mercury concentration, $[\mathrm{Hg}]_{7}$ was assumed to be that of the processed sample (plus spike) that did not contain sorbent (see Appendix, sample 7): 


$$
K_{D}^{\text {walls }}=\frac{\left([\mathrm{Hg}]_{9}+[\mathrm{Hg}]_{7}^{\text {spike }}-[\mathrm{Hg}]_{7}\right) \times L_{i}}{[\mathrm{Hg}]_{7}}
$$

The $K_{D}$ for each sample was then calculated as follows:

$$
K_{D}=\frac{\left([\mathrm{Hg}]_{9}+[\mathrm{Hg}]_{i}^{\text {spike }}-[\mathrm{Hg}]_{i}\right) \times L_{i}-K_{d}^{\text {walls }} \times[\mathrm{Hg}]_{i}}{[\mathrm{Hg}]_{i} \times W_{i}}
$$

An example of an isotherm plot generated during the studies is shown in Fig. 3. Similar plots for the other sorbents have previously been published. ${ }^{5}$ It is clear from the results that SIR-200 was able to remove mercury in the creek water to values below $12 \mathrm{ng} / \mathrm{L}$ (the lowest target goal). Similar removal efficiency was also seen in experiments conducted with Ionac SR-4, Keyle:X, and Mersorb.

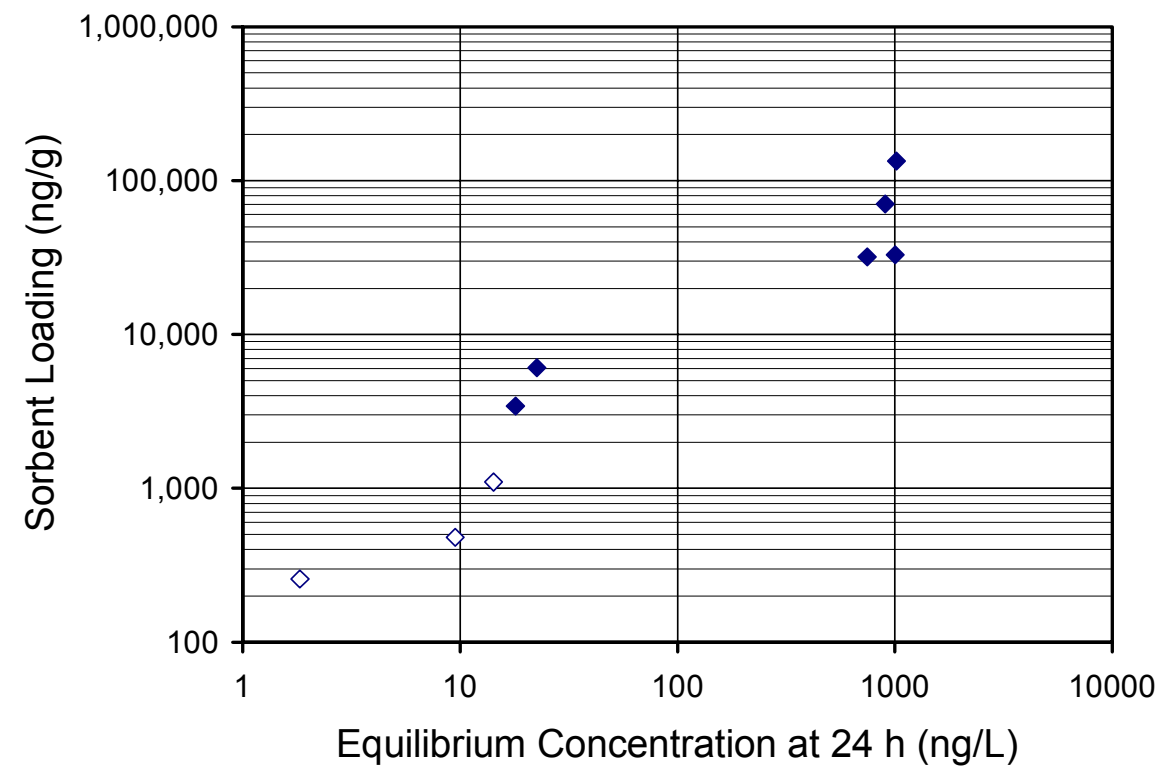

Fig. 3. Isotherm results from multiweight testing of SIR-200 by ResinTech, Inc. Open symbols indicate results from unspiked samples.

The results from the batch testing are summarized in Table 1 for treatment of a 1000-ng/L stream. As noted, the thiol-based resin (Ionac SR-4) had a much higher capacity than all the other resins tested. The batch results indicate that $16,700 \mathrm{~L}$ of Outfall 200 water can be treated for $\$ 1$ in resin cost. This corresponds to a cost of approximately $\$ 0.24 / 1000$ gal water. The flow at Outfall 200 is approximately 2.5 million gallons per day; thus, the average daily cost for the resin would be about $\$ 600$. 
Table 1. Summary results of isotherm testing on UEFPC water ${ }^{a}$

\begin{tabular}{|c|c|c|c|}
\hline Sorbent & $\begin{array}{c}K_{D}\left(_{\text {dry basis })^{b}}\right. \\
(\mathrm{L} / \mathrm{kg})\end{array}$ & $\begin{array}{c}K_{D}{\text { (bed basis })^{c}}^{\left(\mathrm{L} / \mathrm{L}_{\mathrm{BV}}\right)} \\
\end{array}$ & $\begin{array}{c}K_{D}(\text { cost basis })^{d} \\
(\mathrm{~L} / \$)\end{array}$ \\
\hline $\begin{array}{l}\text { Sybron Chemicals, Inc. } \\
\text { Ionac SR-3 (thiouronium) }\end{array}$ & 50,000 & 26,700 & 2,200 \\
\hline $\begin{array}{l}\text { Sybron Chemicals, Inc. } \\
\text { Ionac SR-4 (thiol) }\end{array}$ & $500,000^{e}$ & 235,000 & 16,700 \\
\hline $\begin{array}{l}\text { ResinTech, Inc. } \\
\text { SIR-200 (thiol) }\end{array}$ & 80,000 & 48,800 & 1,950 \\
\hline $\begin{array}{l}\text { SolmeteX, Inc. } \\
\text { Keyle:X (proprietary) }\end{array}$ & 250,000 & 67,700 & $540-970$ \\
\hline $\begin{array}{l}\text { Dynaphore, Inc. } \\
\text { Forager Sponge (amine) }\end{array}$ & 3,000 & $270^{f}$ & 54 \\
\hline $\begin{array}{l}\text { Nucon International, Inc. } \\
\text { Mersorb } 1.5 \mathrm{~mm}\end{array}$ & 70,000 & 39,500 & 7,900 \\
\hline
\end{tabular}

${ }^{a}$ The $K_{D}$ values were estimated at $1000 \mathrm{ng}$ mercury /L.

${ }^{b}$ Calculated as sorbent capacity (ng mercury/kg dry sorbent) $\div[1000$ (ng mercury/L water) $]$.

${ }^{c}$ Calculated as $\left[K_{D}(\right.$ dry basis $\left.)\right] \times(1-$ moisture content $) \times[$ bulk density $(\mathrm{kg} / \mathrm{L})]$.

${ }^{d}$ Calculated as $\left[K_{D}(\right.$ bed basis $\left.)\right] \div\left[\operatorname{cost}\left(\$ / \mathrm{L}_{\mathrm{BV}}\right)\right]$.

${ }^{e}$ Extrapolated value.

${ }^{f}$ This value can be increased by packing the Forager Sponge more tightly.

\subsection{SHORT-TERM COLUMN STUDIES}

The results of the short-term studies conducted at the UEFPC are shown in Figs. 4 and 5. The sorbents SIR-200, Keyle:X, and Duolite GT-73 were found to give the best performance for removal of low-level mercury. A large deviation in the measured mercury concentration in the column inlets indicated a wide variability in mercury levels during the first study. The fractional breakthrough was calculated as the ratio between outlet concentration from a particular column divided by the outlet concentration of the empty column, which operates in parallel. In these short-term tests, SIR-200, Keyle:X, and Duolite GT-73 were able to reduce the mercury concentration to less than the proposed 51-ng/L NPDES limit for water flow rates of less than or equal to $1 \mathrm{BV} / \mathrm{min}$. It is interesting to note that the SR-4 resin, which had been shown to have a high loading capacity for mercury, did not perform as well as the other thiol-based resins. Detailed results of the short-term column study at the UEFPC have been published elsewhere. ${ }^{4}$ 


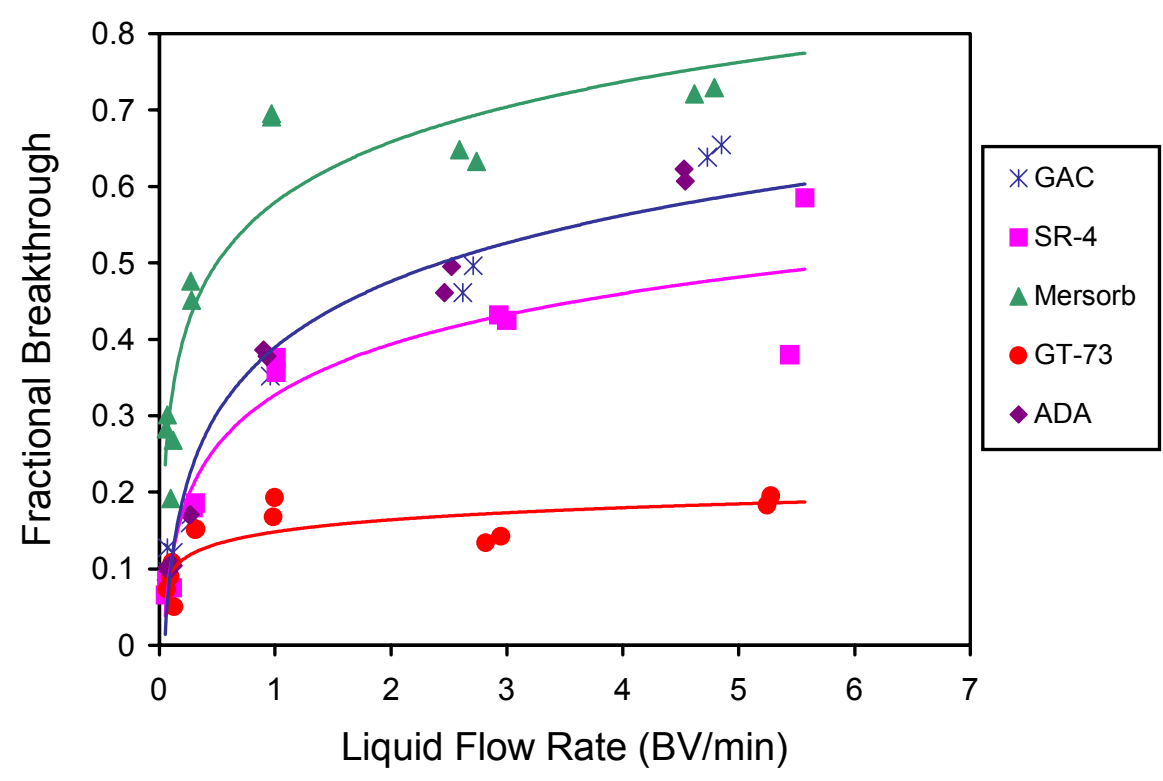

Fig. 4. Results of the first set of short-term column studies at the UEFPC. Granular activated carbon, the baseline technology, was tested for comparison. Solid lines indicate empirical data trends. Data were collected over a 1-week period. The inlet concentration to the columns was $974 \mathrm{ng} / \mathrm{L}$, on average, with a standard deviation of $729 \mathrm{ng} / \mathrm{L}$.

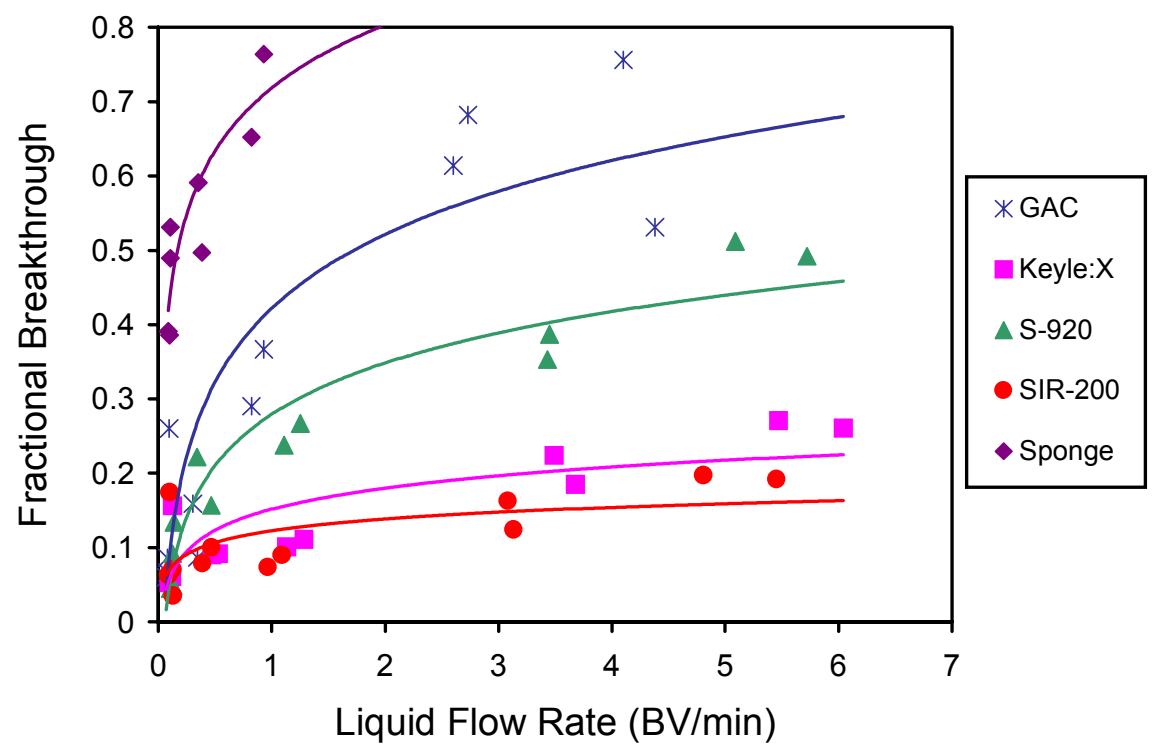

Fig. 5. Results of the second set of short-term column studies at the UEFPC. Granular activated carbon, the baseline technology, was tested for comparison. Solid lines indicate empirical data trends. Data were collected over a 1-week period. The inlet concentration to the columns was $591 \mathrm{ng} / \mathrm{L}$, on average, with a standard deviation of $73 \mathrm{ng} / \mathrm{L}$. 
The data displayed in Figs. 4 and 5 were constructed on the basis of total mercury content in unfiltered samples. At two sampling events (at the highest and lowest flow rates), filtered ( $0.45-\mu \mathrm{m}$-pore-size filter) samples were collected during the two runs. The results are displayed in Fig. 6. The results clearly show that a fraction of the mercury in the effluent can be filtered out (6-90\% of the total mercury). However, it is difficult to deduce if this amount is a constant or a fraction dependent on the concentration. In Fig. 7, the filtered effluent concentration has been plotted as a function of the unfiltered effluent concentration. A trend line corresponding to the straight-line equation has been added to correlate the data. The implication of the straight-line equation is that there is a threshold concentration $(57.6 \mathrm{ng} / \mathrm{L})$ below which all mercury would be removed via filtration. Statistical evaluation of the threshold concentration indicates that, with $95 \%$ confidence, it is between 30 and $89 \mathrm{ng} / \mathrm{L}$. If the data collected from the empty column are ignored, the threshold value would be $62.4 \mathrm{ng} / \mathrm{L}$.

Collected at Lowest Flow Rate
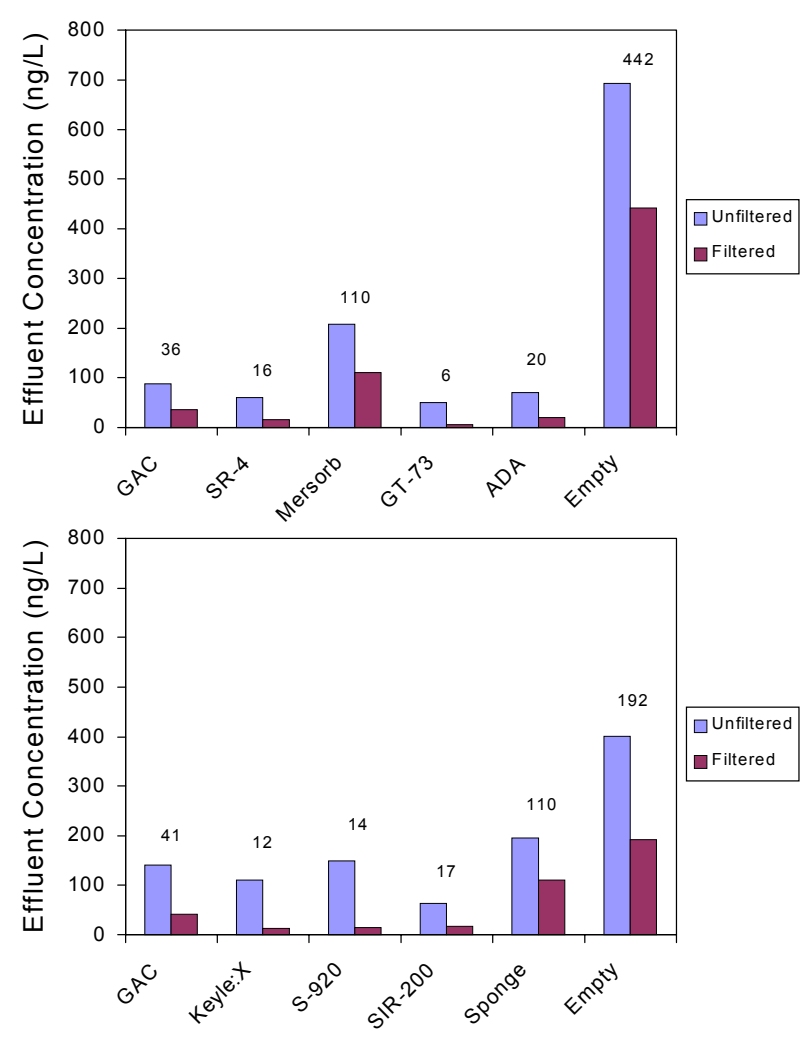

Collected at Highest Flow Rate
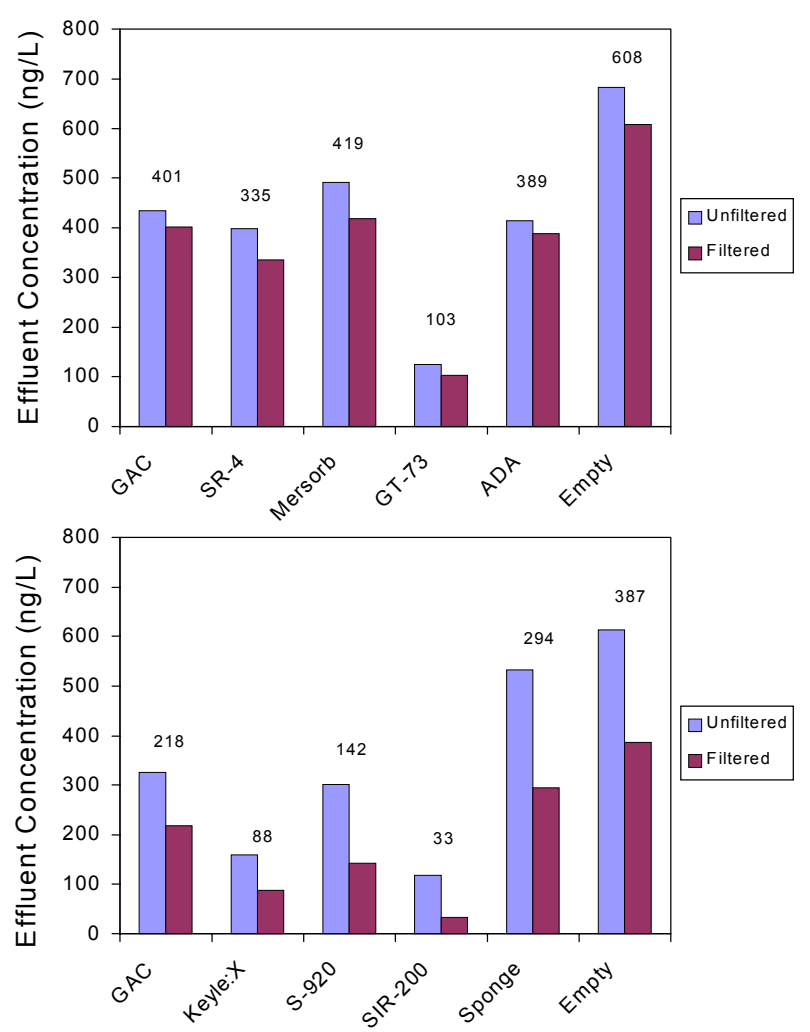

Fig. 6. Results of unfiltered and filtered samples collected during the shortterm column studies conducted at the UEFPC. Values above the bars indicate the filtered mercury concentrations. 


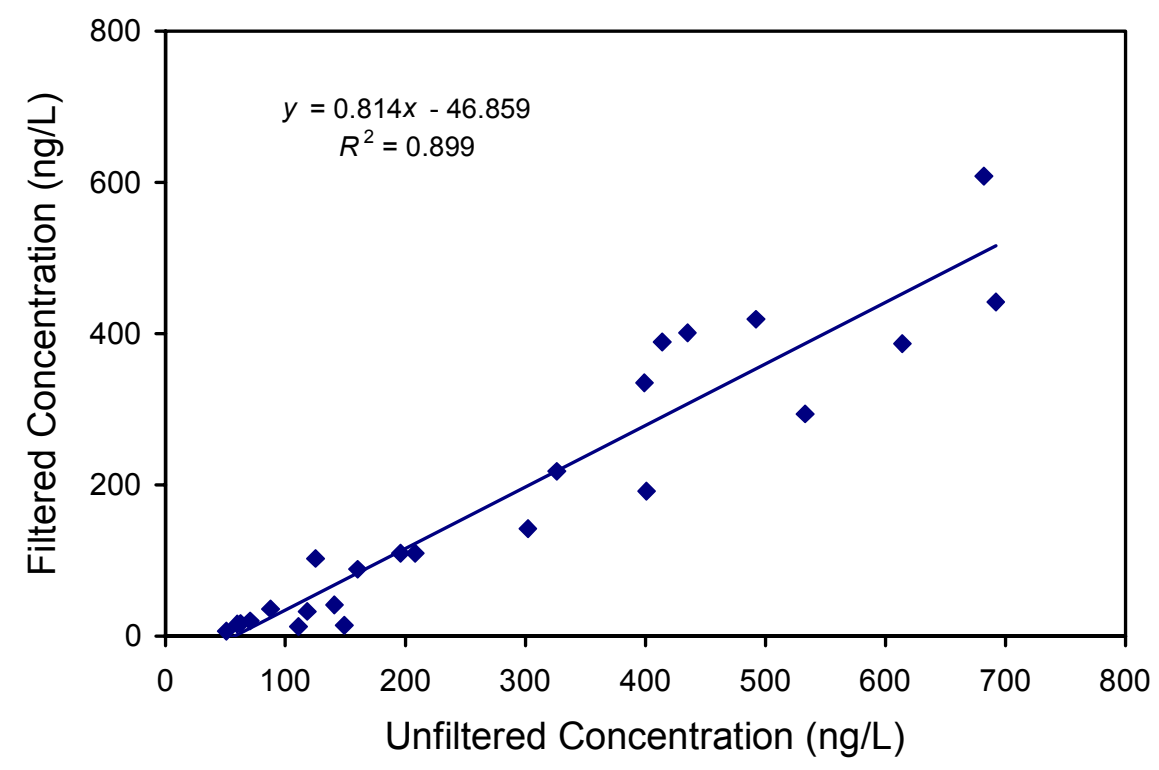

\section{Fig. 7. Summary of the filtration data collected from short-term column studies conducted at the UEFPC.}

Data from early short-term column studies conducted at the NRWTP showed that the mercury removal efficiency of the sorbents varied considerably over time, probably associated with changes in the speciation of the mercury in the wastewater. A few samples of the NRWTP wastewater were analyzed for chemically active (ionic and elemental) mercury to estimate the fraction of the mercury that was easily accessible to the sorbents. These samples were filtered through 0.45 - and $0.02-\mu \mathrm{m}$-pore-size filters. (The 0.02- $\mu \mathrm{m}$-pore-size filter will remove colloidal particles.) The results are displayed in Fig. 8.

These results suggest that a significant fraction of the mercury in the wastewater at the NRWTP is associated with particulates. It is likely that the change in performance of the sorbents at different times is associated with changes in the fraction of total mercury that is in a chemically active form. Chlorinating the water, which could convert the bound mercury to an ionic form, improved the performance of some of the sorbents. Overall, the Keyle:X resin gave the best performance with chlorinated water, followed by SIR-200, in the short-term studies at the NRWTP. ${ }^{6}$ 


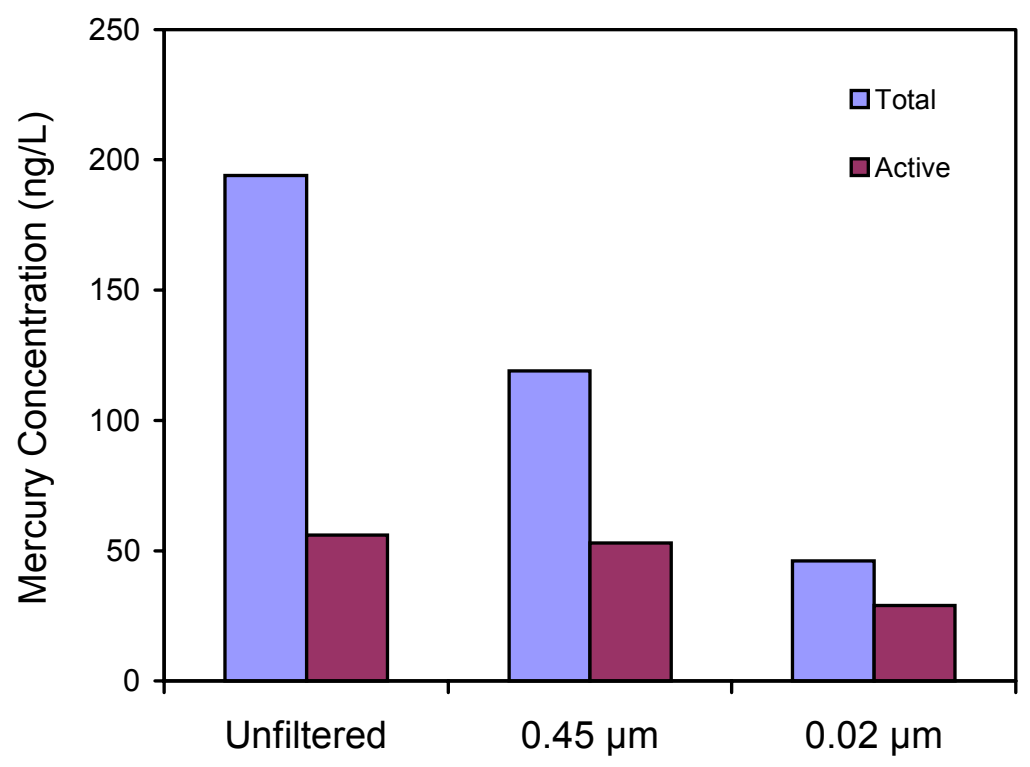

Fig. 8. Results of an NRWTP filtration study of water entering the smallscale treatment system (upstream of the $1-\mu \mathrm{m}$-pore-size prefilter).

\subsection{LONG-TERM COLUMN STUDIES}

Based on the results from the short-term column studies conducted at both locations, several thiol-based sorbents were selected for use in the long-term studies. In addition to the previously tested sorbents, SAMMS was included in the study. The results of the long-term column studies conducted at the UEFPC and NRWTP are shown in Figs. 9 and 10 for the two best-performing sorbents at each site. Two sorbents, Keyle:X and SIR-200, performed well at the UEFPC for several months. It is interesting to note that these sorbents performed very similarly. The best performance at the NRWTP was noted for a Keyle:X sorbent bed, processing water that had been pretreated with hypochlorite (1-2 mg/L total residual chlorine). At the end of the first segment of the study (Fig. 10), chlorine was noted in the effluent of the column containing the Keyle:X sorbent; this had not previously been the case. The SAMMS sorbent bed gave the second best performance at the NRWTP. The remaining data collected from the long-term study are displayed in Figs. 11 and 12. As is noted, the other thiol-based sorbents tested performed similarly at both sites. In these figures, $100,000 \mathrm{BV}$ is approximately equal to $7000 \mathrm{~L}$ (1850 gal), and the average bed volumes were used to calculate $\mathrm{x}$-axis values. 


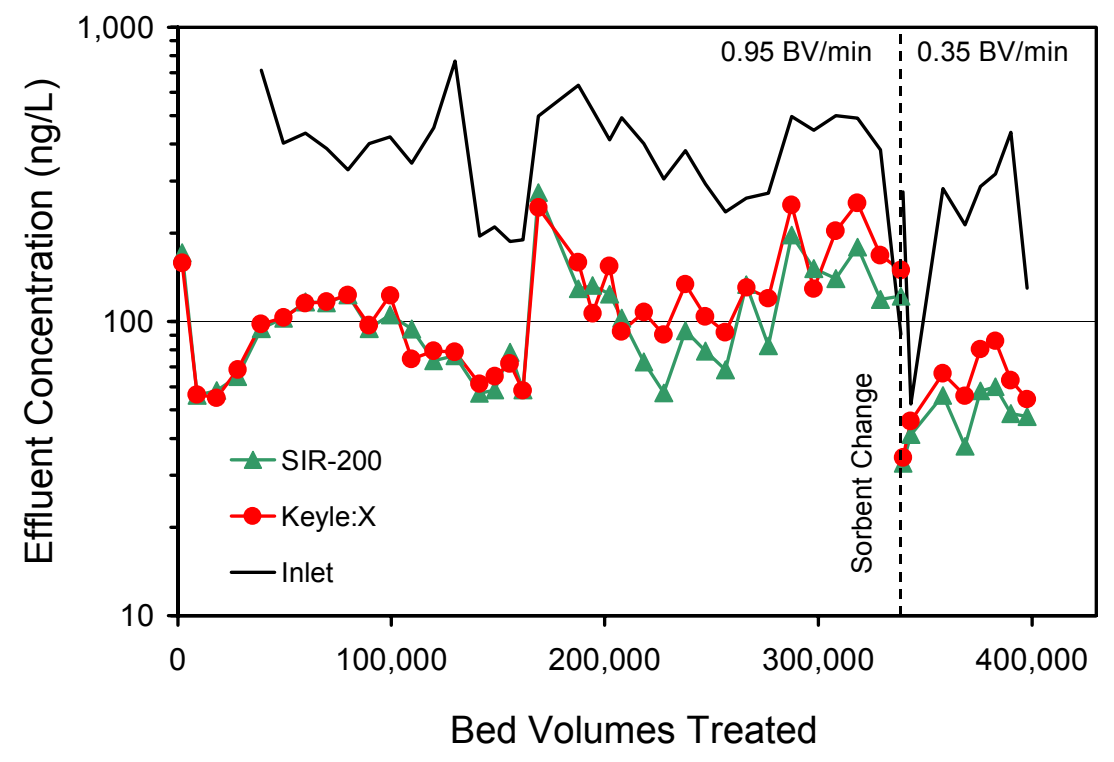

Fig. 9. Effluent concentrations from the columns used in the long-term study at the UEFPC. The flow rate was approximately $0.95 \mathrm{BV} / \mathrm{min}$ and then decreased to $0.35 \mathrm{BV} / \mathrm{min}$ after $340,000 \mathrm{BV}$, when the sorbent was changed. The influent concentration to the columns was measured downstream of the prefilter.

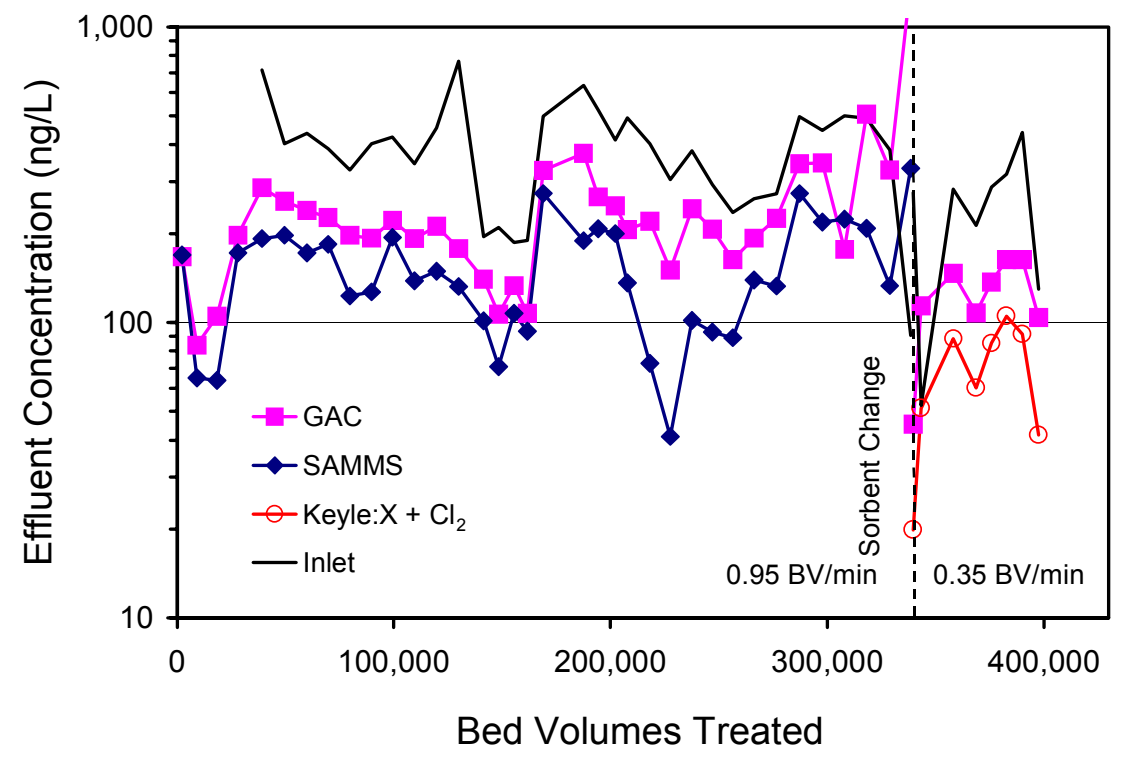

Fig. 10. Effluent concentrations from the columns used in the long-term study at the NRWTP. The flow rate was approximately $0.3 \mathrm{BV} / \mathrm{min}$ and then decrease to $0.15 \mathrm{BV} / \mathrm{min}$ after $85,000 \mathrm{BV}$, when the sorbent was changed. The influent concentration to the columns was measured downstream of the prefilter. 


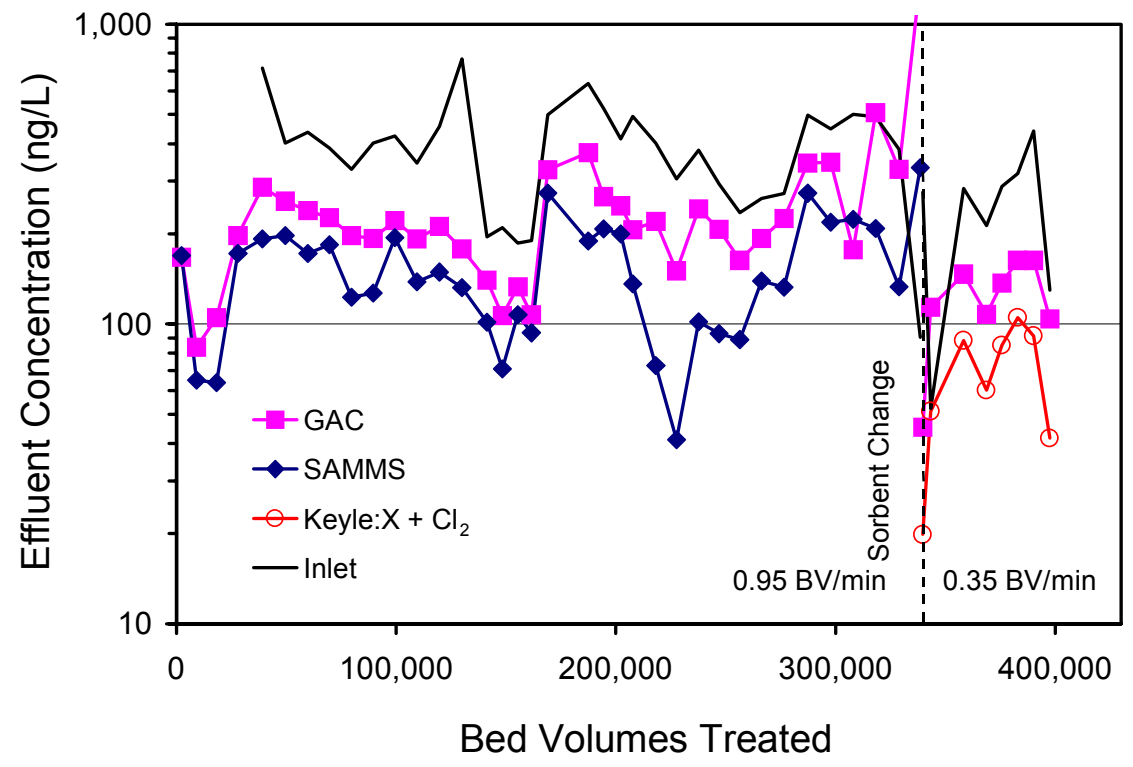

Fig. 11. Effluent concentrations from the columns used in the long-term study at the UEFPC. The flow rate was approximately $0.95 \mathrm{BV} / \mathrm{min}$ and then decreased to $0.35 \mathrm{BV} / \mathrm{min}$ after $340,000 \mathrm{BV}$, when the sorbent was changed. The influent concentration to the columns was measured downstream of the prefilter.

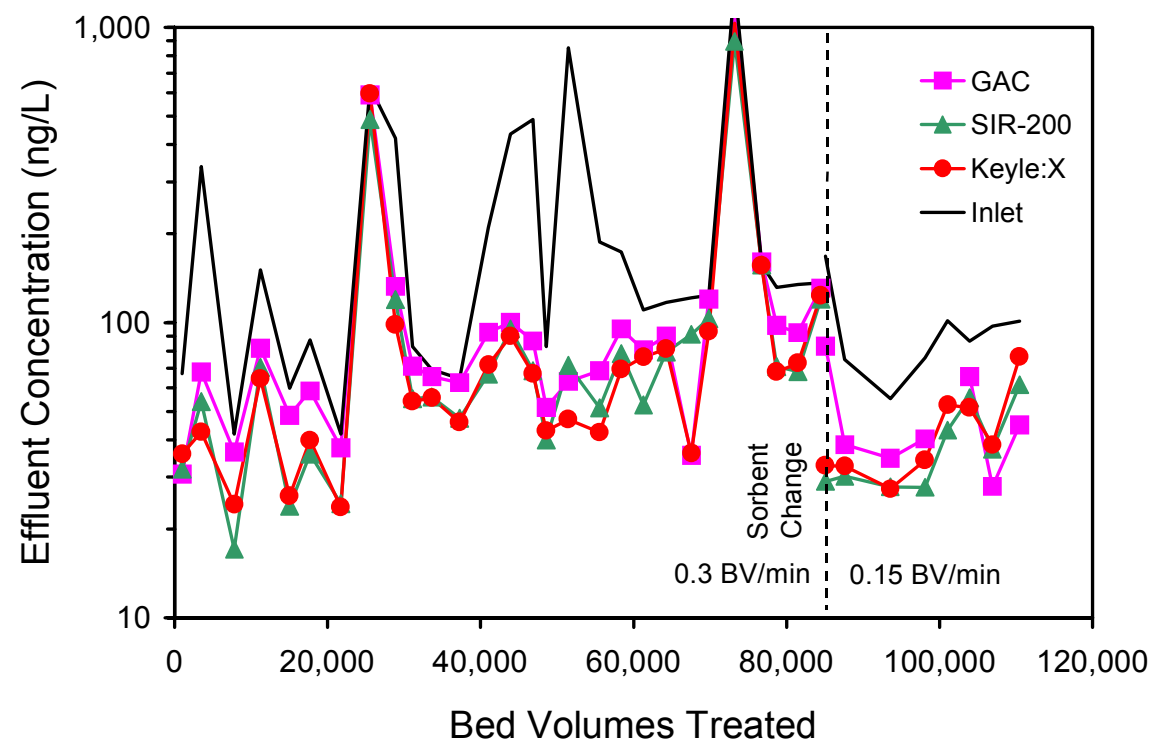

Fig. 12. Effluent concentrations from the columns used in the long-term study at the NRWTP. The flow rate was approximately $0.3 \mathrm{BV} / \mathrm{min}$ and then decreased to $0.15 \mathrm{BV} / \mathrm{min}$ after $85,000 \mathrm{BV}$, when the sorbent was changed. The influent concentration to the columns was measured downstream of the prefilter. 
On four sample occasions, filtered (0.2- and $0.45-\mu \mathrm{m}$ filter) samples were collected from the column effluents. The results are displayed in Figs. 13 and 14. The results clearly show that a fraction of the mercury in the effluent from each of the sorbent columns can be filtered out. It should be noted that the mercury levels in the effluent from the columns at the NRWTP were quite high during the second of these campaigns, when filtered samples were collected. In Fig. 15, the filtered effluent concentration has been plotted as a function of the unfiltered effluent concentration for samples taken at the two locations. Trend lines corresponding to the straight-line equations have been added to correlate the data. The implication of the straight-line equation is that a threshold total concentration (7-10 $\mathrm{ng} / \mathrm{L})$ exists, below which all mercury would be removed via filtration. This range is lower that the one found during the short-term studies (Fig. 7).

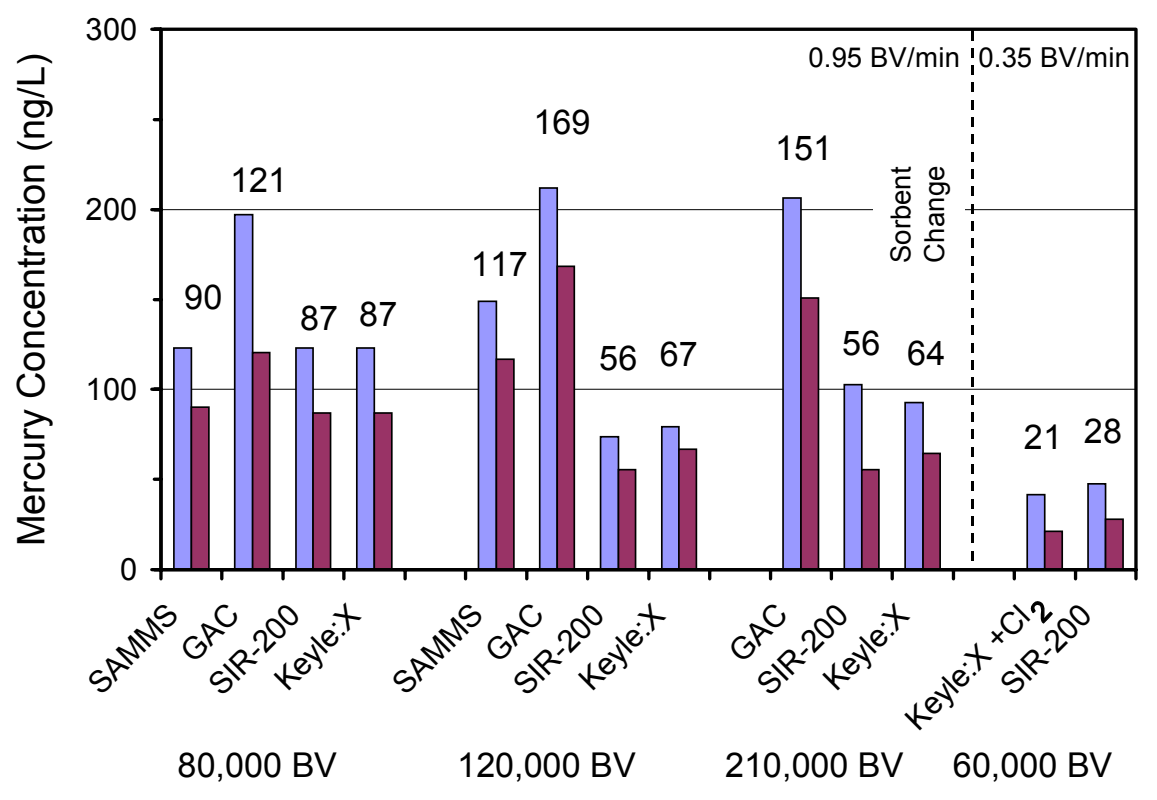

Fig. 13. Summary of results from filtered and unfiltered samples collected at the UEFPC at different times during the study. The first set of samples, collected at $80,000 \mathrm{BV}$, were filtered through a $0.45-\mu \mathrm{m}$-pore-size filter; the others, through a $0.2-\mu \mathrm{m}$-pore-size filter. Values above the bars indicate the filtered mercury concentrations. 


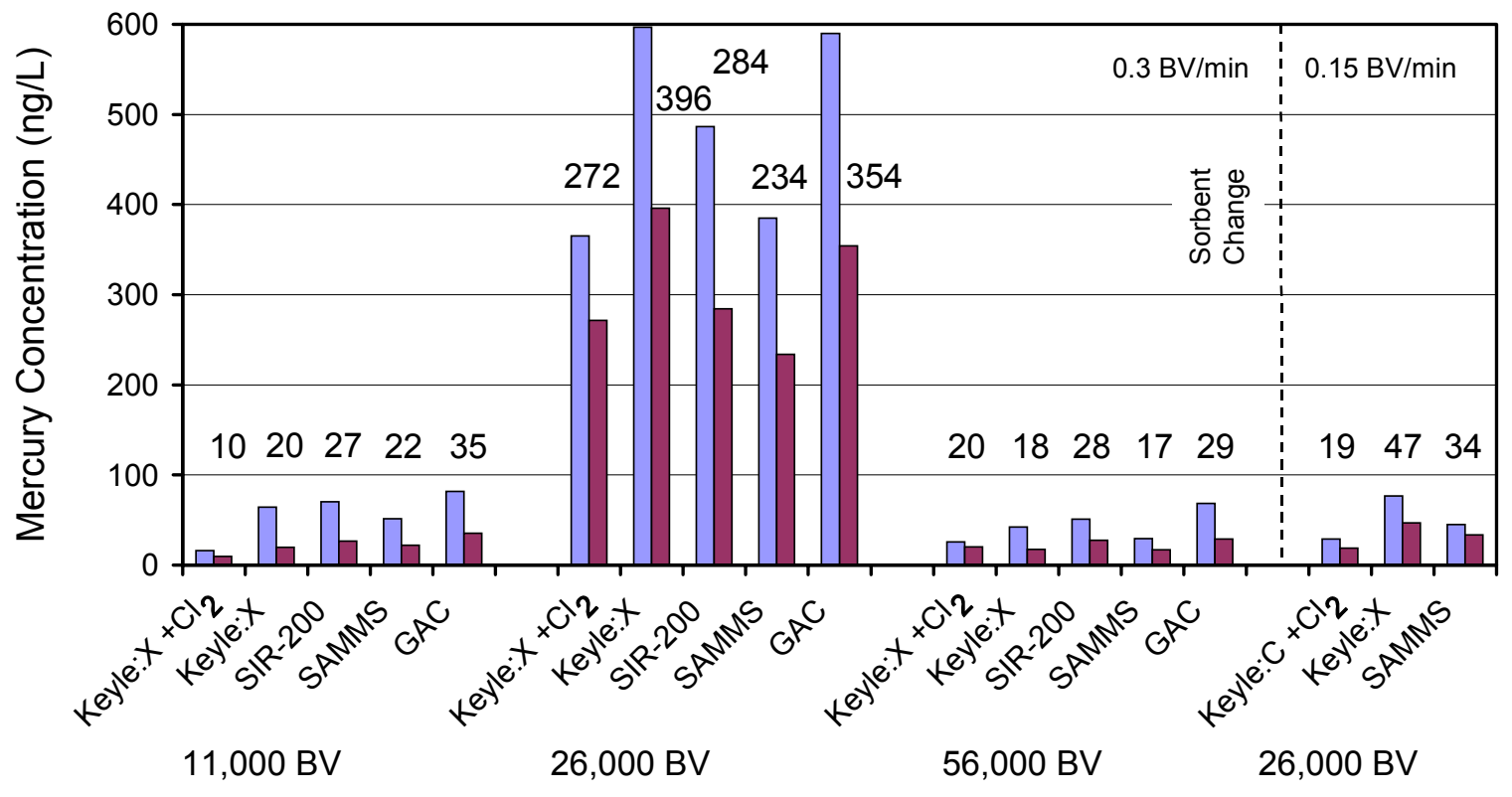

Fig. 14. Summary of results from filtered and unfiltered samples collected at the NRWTP at different times during the study. The first set of samples, collected at $11,000 \mathrm{BV}$, was filtered through a $0.45-\mu \mathrm{m}$-pore-size filter; the others, through a $0.2-\mu \mathrm{m}$-pore-size filter. Values above the bars indicate the filtered mercury concentrations.

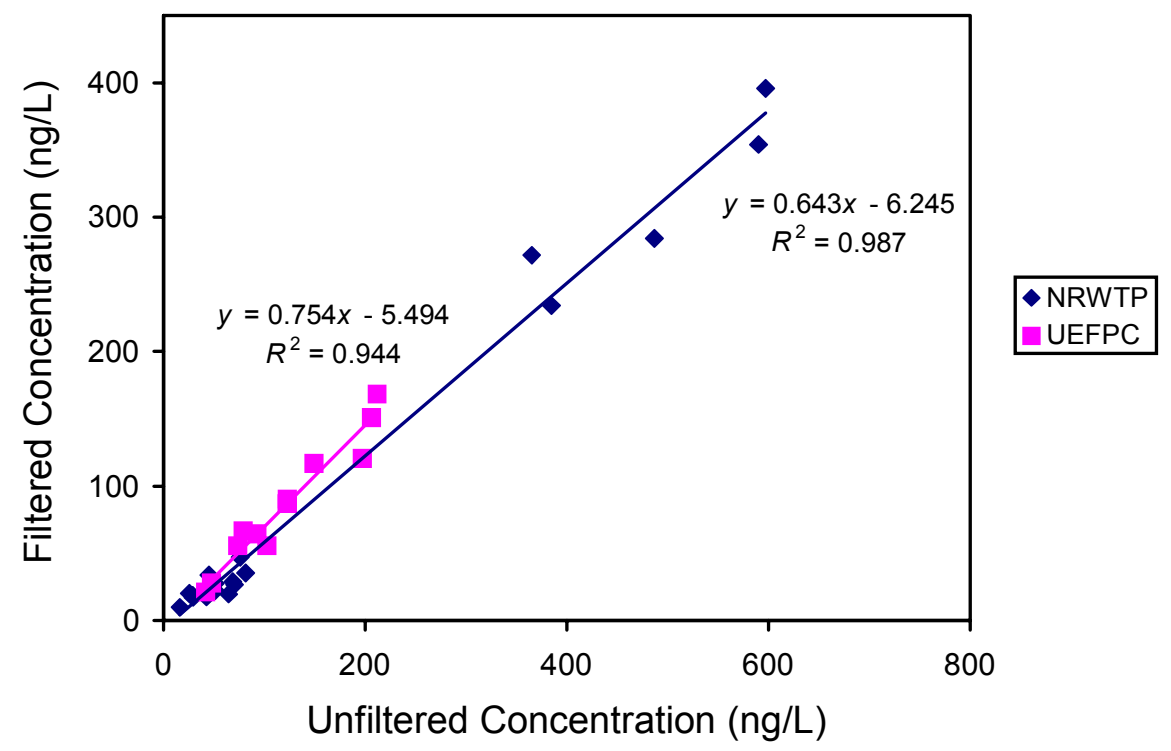

Fig. 15. Summary of the filtration data collected from long-term column studies. 


\section{MATHEMATICAL MODELING}

\subsection{SHORT-TERM COLUMN STUDIES}

Simple kinetic modeling was performed to elucidate the difference in removal efficiency by the sorbents. The general equations presented by Kawamura et al. ${ }^{8}$ can be simplified, assuming that there is very little loading on the sorbents during the experiment, to yield (see Sect. 8 for nomenclature)

$$
v \frac{d C}{d z}+\frac{(1-\varepsilon)}{\varepsilon} \frac{d \bar{q}}{d t}=0, \text { and }
$$

and

$$
\frac{d \bar{q}}{d t}=k_{f}\left(C-C_{s}\right)=k_{p}\left(q_{s}-\bar{q}\right)=k_{p} K C_{s}
$$

These equations may be combined and integrated (with respect to $z$ ) to yield

$$
-\ln \left(\frac{C_{\text {out }}}{C_{\text {in }}}\right)=\frac{(1-\varepsilon) Z}{\varepsilon v}\left(\frac{1}{k_{p} K}+\frac{1}{k_{f}}\right)^{-1}
$$

The relative size of $k_{p} K$ versus $k_{f}$ gives an indication of the type of resistance (internal or external to the bead) that is dominating the removal efficiency. Generally, a low flow rate may be more likely to have external mass-transfer limitation, while a high flow rate may cause the internal particle diffusion to be rate limiting. The external mass-transfer resistance is usually mathematically predicted, while the internal diffusion is usually measured experimentally. Figure 16 shows modeling of short-term studies of three hypothetical sorbents with different internal diffusivities. The values of $k_{p}$ and $k_{f}$ were calculated using the following correlations: ${ }^{8}$

$$
k_{p}=\frac{60 D_{e f f}}{d^{2}},
$$

and

$$
k_{f}=\frac{11.1 D_{f}}{d^{2}}\left(\frac{1-\varepsilon}{\varepsilon}\right)^{2 / 3}\left(\frac{\mathrm{ScRe}}{1-\varepsilon}\right)^{1 / 3}
$$




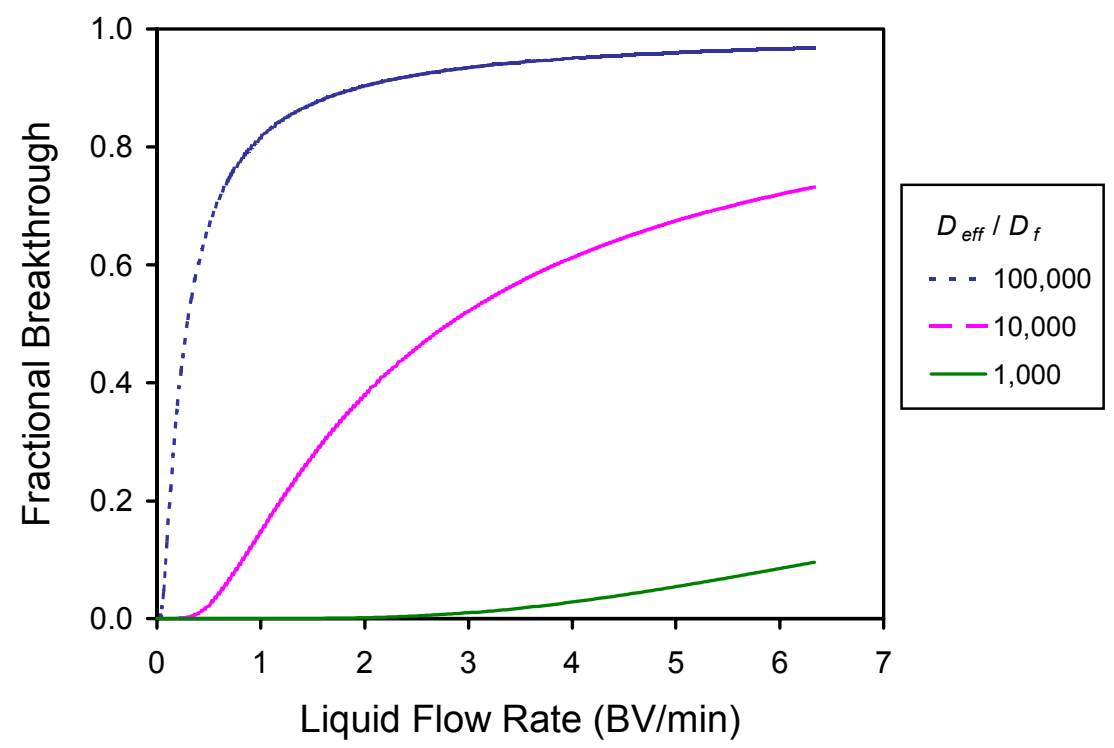

Fig. 16. Mathematical modeling of hypothetical sorbents with different internal diffusivities. The isotherm constant, void fraction, particle diameter, and external diffusivity were $1600,0.4,0.7 \mathrm{~mm}$, and $2.9 \times 10^{-9} \mathrm{~m}^{2} / \mathrm{s}$, respectively, in the modeling study.

Before fitting the data to Eq. (5), the raw data for the short-term column studies (Figs. 4 and 5) conducted at the UEFPC were adjusted (see Fig. 7) for the portion of the total mercury that could be filtered out. The value for $k_{p} K$ was determined to be $\sim 0.35 \mathrm{~s}^{-1}$ for the three thiol-based resins that performed the best. The Mersorb and GAC had $k_{p} K$ values of about 0.46 and $0.10 \mathrm{~s}^{-1}$, respectively. Predicted profiles in short-term column studies are plotted in Fig. 17. It should be noted that this model is for active mercury, not the fraction of the total mercury that remains difficult to adsorb. As a result, the model predicts a zero breakthrough for the lowest flow rates. Predictions to include particle-bound mercury were not attempted, but the shape of the curves should be very similar to those in Fig. 17, shifted upward to allow for a minimal fractional breakthrough.

\subsection{LONG-TERM COLUMN STUDIES}

Column performance is often mathematically modeled using simplified analytical solutions to the differential equations describing the system. This approach is appropriate where the kinetics and equilibrium are simple. Ruthven has summarized such models and solutions. ${ }^{9}$ If a linear equilibrium can be assumed, two equations developed by Rosen can be used to describe the breakthrough. ${ }^{10}$ For solid diffusion limitation (external mass transfer can be neglected), Eq. (8) is used: 


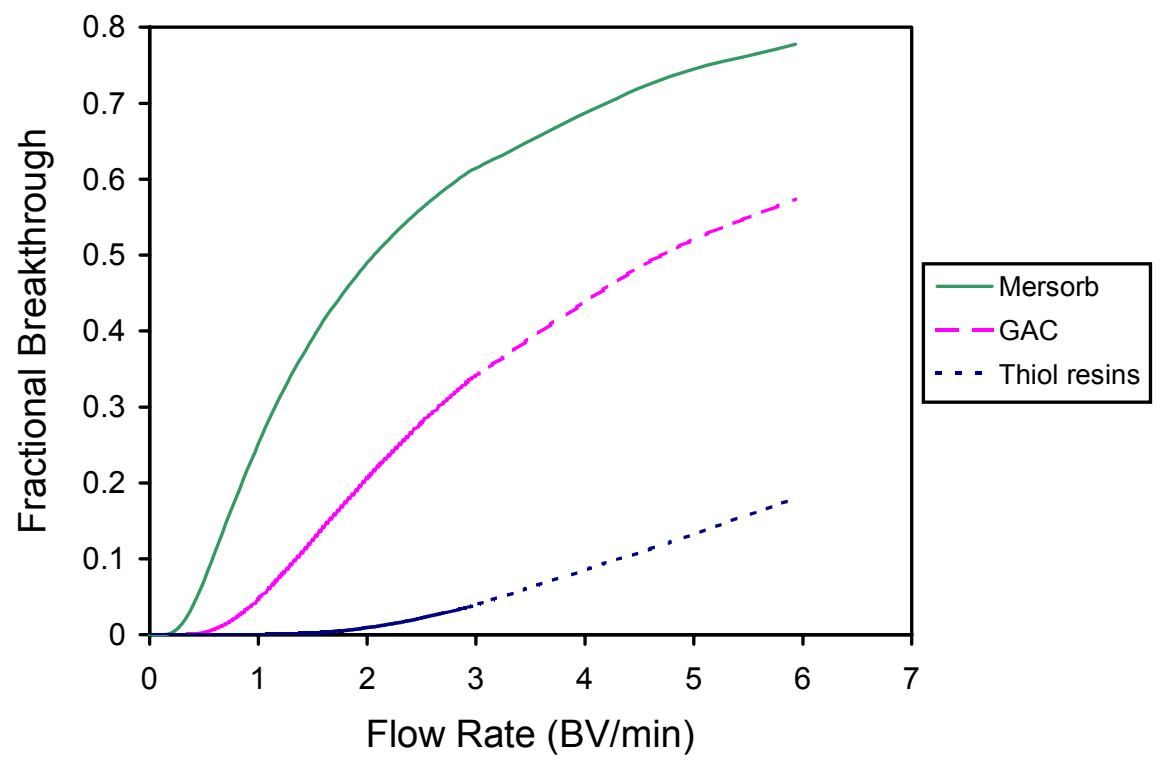

Fig. 17. Prediction of profiles for short-term column studies for removal of free mercury. The actual values for sorbent density and particle size were used with the values for $k_{p} K$ provided in Sect. 5.1.

$$
\frac{C_{o u t}}{C_{\text {in }}}=0.5\left[1+e r f\left(\frac{\frac{3 y}{2 x}-1}{\sqrt{\frac{4}{5 x}}}\right)\right]
$$

If both solid diffusion and external mass transfer must be considered, Eq. (9) may be used:

$$
\frac{C_{\text {out }}}{C_{\text {in }}}=0.5\left[1+e r f\left(\frac{\frac{3 y}{2 x}-1}{\sqrt{\frac{4 v}{x}}}\right)\right],
$$

where

$$
\frac{3 y}{2 x}=\frac{\varepsilon}{K_{D} \rho_{s}}\left(\frac{v_{s} t}{\varepsilon z}-1\right),
$$




$$
\frac{4}{5 x}=\frac{v_{s} d^{2}}{15 D_{s} K_{D} \rho_{s} z}
$$

and

$$
\frac{4 v}{x}=\frac{4 v_{s}}{k_{f} z(1-\varepsilon)}
$$

The mass transfer coefficient for the fluid film may be evaluated from Eqs. (13)-(16): $:^{8,11,12}$

$$
\begin{gathered}
k_{f}=\frac{2.62\left(D_{f} v_{s}\right)^{0.5}}{(1-\varepsilon) d^{1.5}}, \\
k_{f}=\frac{6 D_{f}}{d^{2}}\left(2+0.6 \mathrm{Sc}^{1 / 3} \mathrm{Re}^{1 / 2}\right), \\
k_{f}=\frac{6 D_{f}}{d^{2}}\left(2+1.1 \mathrm{Sc}^{1 / 3} \mathrm{Re}^{0.6}\right),
\end{gathered}
$$

or

$$
k_{f}=\frac{11.1 D_{f}}{d^{2}}\left(\frac{1-\varepsilon}{\varepsilon}\right)^{2 / 3}\left(\frac{\mathrm{Sc} \mathrm{Re}}{1-\varepsilon}\right)^{1 / 3}
$$

Another well-known method for predicting breakthrough is presented in Eq. (17). In this case, a linear rate expression that combines dispersion, film mass transfer, and intraparticle diffusion is used:

$$
\frac{C_{\text {out }}}{C_{\text {in }}}=0.5\left[1+\operatorname{erf}\left(\frac{\sqrt{\frac{3 y}{2 x}}-1}{\sqrt{\frac{1}{5 x^{\prime}}}}\right)\right],
$$

where

$$
\frac{1}{5 x^{\prime}}=\frac{v_{s}}{z}\left(\frac{D_{f} \varepsilon}{v_{s}^{2}}+\frac{1}{(1-\varepsilon) k_{f}}+\frac{d^{2}}{60(1-\varepsilon) D_{e f f}}\right) .
$$

Pressure drop in sorbent columns can be approximated using the following equation:

$$
\Delta p=\frac{\rho_{f} v_{s}^{2} z}{d} \alpha
$$


where

$$
\alpha=\frac{38}{\left(\frac{d v_{s} \rho_{f}}{\mu}\right)^{0.15}}
$$

for $d v_{s} \rho_{f} / \mu>40$ (turbulent flow). For laminar flow,

$$
\alpha=\frac{805}{\left(\frac{d_{p} v_{s} \rho_{f}}{\mu}\right)} .
$$

In Fig. 18, the results of modeling efforts are displayed for two different flow rates. All other parameters for the SIR-200 sorbent are listed in Table 2. As noted when comparing the field data (Fig. 9) with the modeling data, the match is poor. The field data do not show a clear breakthrough pattern that is caused by the loading of the sorbent. Instead, it shows that the effluent concentration is strongly dependent on the inlet concentration and that a slower, more gradual increase is noted than that predicted by the model. The model also predicts that the sorbent would be fully loaded after treating about 70,000 to 80,000 BV. However, the field data indicate that the sorbent continues to remove mercury even after 300,000 BV had been treated. One explanation for this may be that the 24-h batch studies were not long enough to reach a true equilibrium, thus resulting in a low calculated value for $K_{D}$ determination. Some indication exists that it takes more than $120 \mathrm{~h}$ to reach equilibrium in some cases (data not shown).

The calculated effective diffusivity in the sorbent is quite low, about 100 times lower than the average literature values. ${ }^{8}$ Underestimation of $K_{D}$ in the isotherm studies would lead to a lower calculated value of $D_{\text {eff. }}$ Another explanation for the high value of $D_{\text {eff }}$ may be that colloidal particles are blocking the macropore structure and reducing the pore diffusion. 
Table 2. Parameters for modeling column performance

\begin{tabular}{|c|c|c|}
\hline Parameter & Value & Comment \\
\hline $\mathcal{E}$ & $0.39 \mathrm{~m}^{3} / \mathrm{m}^{3}$ & \\
\hline$\rho_{s}$ & $625 \mathrm{~kg} / \mathrm{m}^{3}$ & \\
\hline$d$ & $0.0007 \mathrm{~m}$ & Spherical particle \\
\hline$K_{D}$ & $60 \mathrm{~m}^{3} / \mathrm{kg}$ & $\begin{array}{l}\text { From Fig. } 3 \text {, corrected for } \\
\text { moisture }\end{array}$ \\
\hline$D_{\text {eff }}$ & $4.14 \times 10^{-14} \mathrm{~m}^{2} / \mathrm{s}$ & $\begin{array}{l}\text { Calculated from the short-term } \\
\text { modeling data }\left(k_{p} K=0.336\right)\end{array}$ \\
\hline$D$ & $0.0254 \mathrm{~m}$ & \\
\hline$Z$ & $0.127 \mathrm{~m}$ & \\
\hline$D_{f}$ & $2.9 \times 10^{-9} \mathrm{~m}^{2} / \mathrm{s}$ & \\
\hline$C_{i n}$ & $365 \mu \mathrm{g} / \mathrm{m}^{3}$ & $365 \mathrm{ppt}$ \\
\hline$v_{s}$ & $\begin{array}{c}2.01 \times 10^{-3} \mathrm{~m} / \mathrm{s} \text { and } \\
7.40 \times 10^{-4} \mathrm{~m} / \mathrm{s}\end{array}$ & $\begin{array}{l}\text { Equivalent to } 0.95 \mathrm{BV} / \mathrm{min} \text { and } \\
0.35 \mathrm{BV} / \mathrm{min}\end{array}$ \\
\hline$\mu$ & $0.001 \mathrm{~Pa} \mathrm{~s}$ & $1 \mathrm{cP}$ \\
\hline$\rho_{f}$ & $997 \mathrm{~kg} / \mathrm{m}^{3}$ & \\
\hline
\end{tabular}

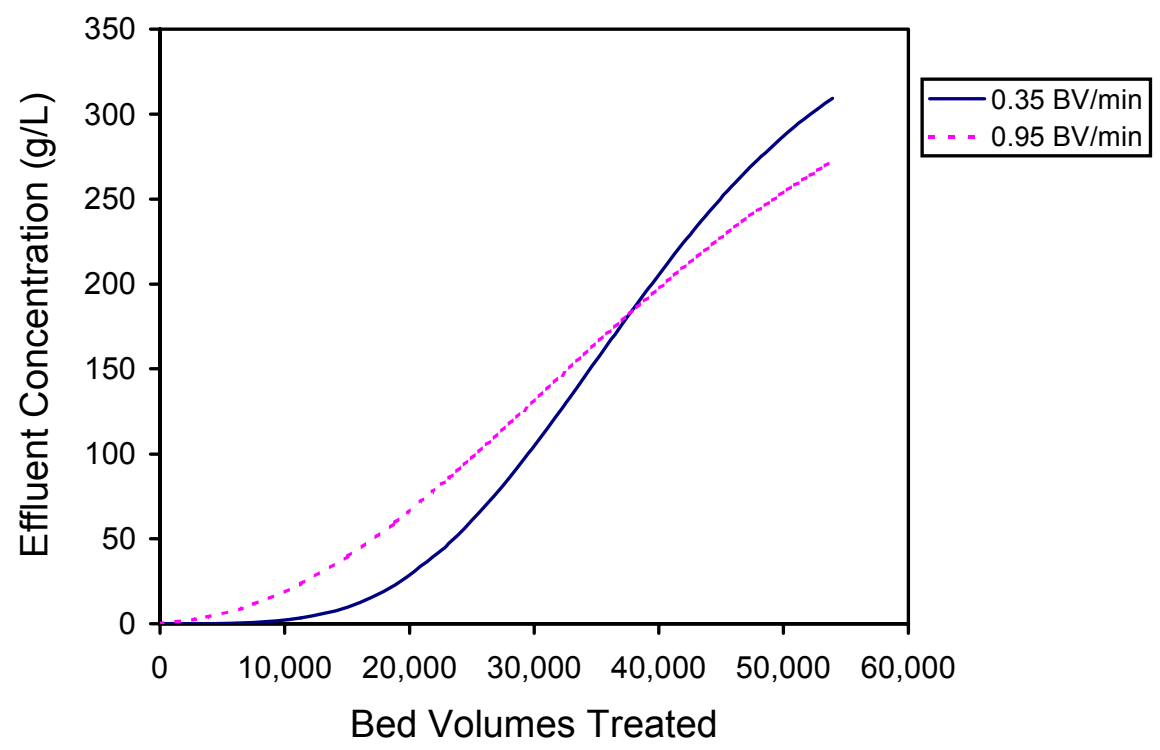

Fig. 18. Results of mathematical modeling of SIR-200 resin. The linear rate expression was used [Eq. (17)], and the fluid-phase mass transfer coefficient, $k_{f}$, was estimated as an average of the values calculated from Eqs. (13)-(16). 


\subsection{WALL EFFECTS}

During the course of this work, some sorbent manufacturers raised questions about possible wall effects in small-scale column studies. The following is a theoretical derivation of wall effects in sorption columns with spherical packing based on work published by Martin. ${ }^{13}$

For spherical packing materials, the void fraction $(\varepsilon)$ is equal to $0.39 .^{13}$ The wall effects occur in a distance within half a particle diameter from the wall of the column. The local porosity at the wall is 1.0 and the minimum porosity is, on average, 0.23 at $d / 2$ from the wall. Thus, a simple model of an adsorption column may be constructed by assuming that the column consists of two sections: an inner core with a uniform porosity of 0.39 and a shell surrounding the core with a thickness of $d / 2$ (Fig. 19). The average porosity of the shell is dependent on the diameters of the column and particle and is given by

$$
\bar{\varepsilon}_{s}=1-\frac{2}{3}\left(\frac{\frac{D}{d}-\frac{7}{8}}{\frac{D}{d}-\frac{1}{2}}\right)\left(1-\varepsilon_{\min }\right)
$$

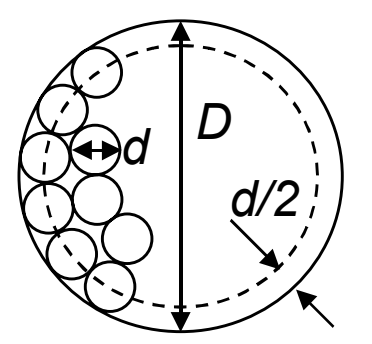

Fig. 19. Cross section of column packed with spherical packing.

The fraction of the column cross-sectional area where wall effects occur is described in Eq. (23):

$$
\varphi=\frac{2 d}{D}-\left(\frac{d}{D}\right)^{2}
$$

Since the porosities of the two sections (core and shell) are different, the flow rate in the two sections will not be the same. The difference in flow may be estimated by setting up a pressure drop-flow rate equation for each of the sections and then setting the pressure drop to be equal. If Ergun's equation ${ }^{14}$ is used as the pressure drop-flow rate relationship, the relationship between the empty-bed superficial velocity for the shell and core is given by

$$
\omega=\frac{\bar{v}_{s, s}}{v_{s, c}}=\frac{\varphi(1-\kappa)-1+\left([\varphi(1+\kappa)-1]^{2}+4(\varphi+M E)(1-\varphi+E) \kappa\right)^{0.5}}{2(\varphi+M E)},
$$


with

$$
\begin{gathered}
\kappa=\left(\frac{1-\varepsilon_{c}}{1-\bar{\varepsilon}_{s}}\right)^{2}\left(\frac{\bar{\varepsilon}_{s}}{\varepsilon_{c}}\right)^{3}, \\
M=\frac{1-\varepsilon_{c}}{1-\bar{\varepsilon}_{s}},
\end{gathered}
$$

and

$$
E=\frac{1.75}{150} \frac{d v_{s} \rho_{f}}{\left(1-\varepsilon_{c}\right) \mu}
$$

The relationship between the superficial velocity in the core and overall superficial velocity is described by

$$
v_{s, c}=\frac{v_{s}}{1-\varphi+\omega \varphi} .
$$

The bulk density of the packing in the shell may be calculated from the density of the packing in the core and the knowledge concerning the different porosities by

$$
\rho_{s, s}=\rho_{s, c} \frac{1-\bar{\varepsilon}_{s}}{1-\varepsilon_{c}} .
$$

The following approach may the be used to evaluate the wall effects for a column operating at an overall superficial velocity of $v_{s}$ :

1. Calculate $\bar{\varepsilon}_{s}, \varphi$, and $\omega$ from Eqs. (22), (23) and (24).

2. Set $\varepsilon_{c}=\varepsilon$, and calculate $v_{s, c}$ from Eq. (28).

3. Calculate the mass transfer coefficient using core parameters and Eq. (13), (14), (15), or (16).

4. Calculate the effluent concentration from the core at time $t$ using Eq. (8), (9), or (17).

5. Calculate $\bar{v}_{s, s}$ and $\rho_{s, s}$ from Eqs. (24) and (29).

6. Calculate the mass transfer coefficient using shell parameters and Eq. (13), (14), (15), or (16).

7. Calculate the effluent concentration from the shell at time $t$ using Eq. (8), (9), or (17).

8. Using the following equation, calculate the observed outlet concentration, combining the flows from the shell and the core:

$$
C_{\text {out }}=\frac{1}{v_{s}}\left(C_{\text {out }, c}[1-\varphi] v_{s, c}+C_{o u t, s} \varphi \bar{v}_{s, s}\right)
$$

The largest particle used in this study was the Mersorb 1.5-mm sorbent. This pellet sorbent was also the one performing poorly in the short-term column study. In Fig. 20, a short-term column experiment has been modeled both with and without wall effects for a sorbent with the same characteristics as a spherical Mersorb particle. As noted, the wall effect had very little influence on the overall performance, even 
though $11 \%$ of the cross-sectional area of the column is in the shell close to the wall. An argument can be made regarding the modeling represented in Fig. 20 since some of the parameters (specifically $D_{\text {eff }}$ ) were estimated without considering wall effects (see Sect. 5.1). One way of correcting for that is to use a ruleof-thumb value for $D_{\text {eff }}$ of $D_{f} / 100 .^{15}$ This results in a more pronounced difference in the fractional breakthrough but predicts that the breakthrough would be in the range of $7-14 \%$ at $6 \mathrm{BV} / \mathrm{min}$. This prediction is not supported by the field data, which showed a much higher breakthrough. Thus, if the preceding theoretical approach is sound, it must be concluded that the difference in performance between sorbents in the short-term studies cannot be explained by the wall effects. Instead, particle diameter and low intraparticle diffusion are more likely reasons for the performance difference. This is also supported by the poor performance of the SR-4 and S-920 sorbents in the short-term column studies (Figs. 4 and 5). These sorbents are of the same size as the other resin sorbents. However, they did not perform as well as the others (GT-73, Keyle:X, and SIR-200), again indicating that the internal diffusion is rate limiting.

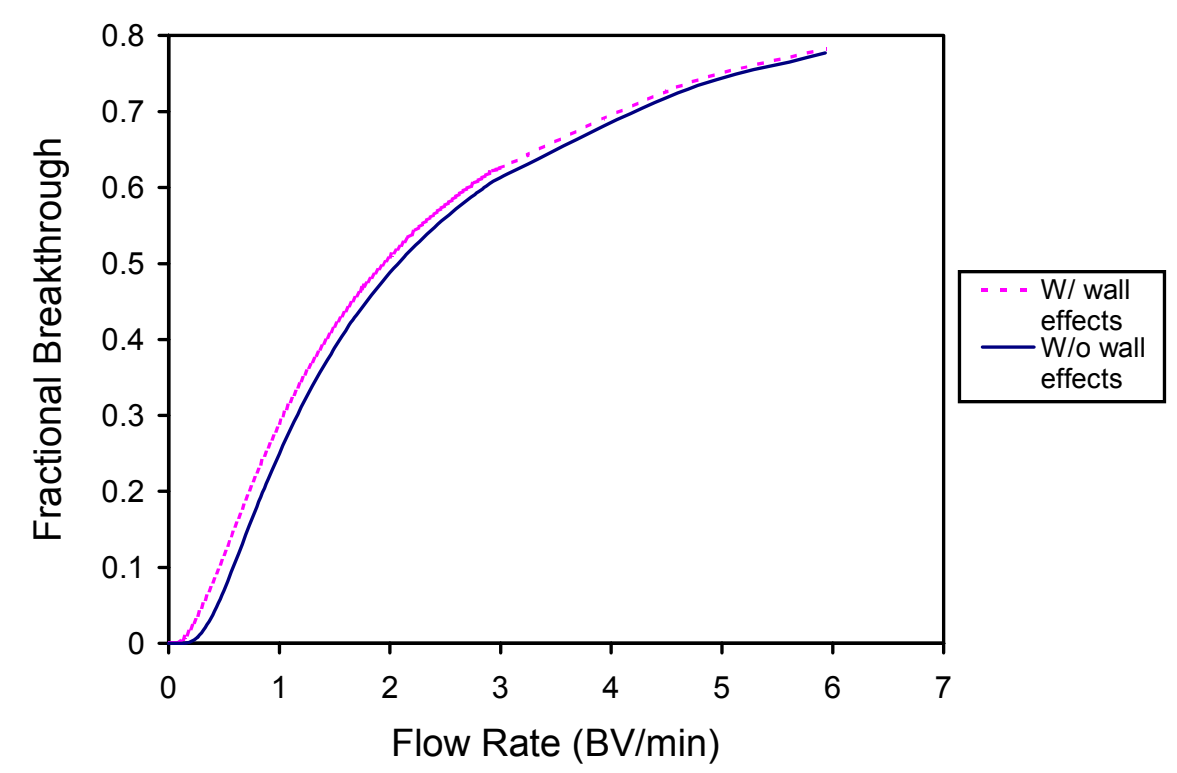

Fig. 20. Predicting wall effects during short-term column studies for the Mersorb 1.5-mm sorbent. The isotherm constant $(K)$, void fraction, particle diameter, fluid diffusivity, and internal effective diffusivity were 58,$500 ; 0.39 ; 1.5 \mathrm{~mm}$; $2.9 \times 10^{-9} \mathrm{~m}^{2} / \mathrm{s}$, and $3.0 \times 10^{-14} \mathrm{~m}^{2} / \mathrm{s}$, respectively, in the modeling study.

\section{COST FOR SMALL-SCALE TREATMENT SYSTEMS}

The cost for small-scale skid-mounted water treatment systems has been summarized by Gumerman et al. ${ }^{16}$ The construction cost as well as operation and maintenance (O\&M) costs are shown in Fig. 21 as a function of the active bed volume for a pressure GAC system. The construction cost includes columns of 
5-ft bed depth with various diameters, piping, surface and backwash pumps, equipment housing, and an initial charge of carbon. Not included are supply water handling (e.g., pumps), water preconditioning (e.g., filtration), and carbon handling (e.g., feed hopper, conveyers). Only the largest design includes two columns. The 1998 cost was extrapolated from the 1983 cost by using the Chemical Engineering Index. Electricity and labor cost were estimated at $\$ 0.10 / \mathrm{kWh}$ and $\$ 40 / \mathrm{h}$, repectively. It should be noted that the calculation of O\&M costs assumes that the system is automated with only routine maintenance required. The annual cost of carbon replacement was not included in the O\&M cost but may be estimated from Fig. 22 , where the cost is displayed as function of bed volume for different replacement frequencies. The replacement frequency depends on the loading capacity of mercury on the GAC.

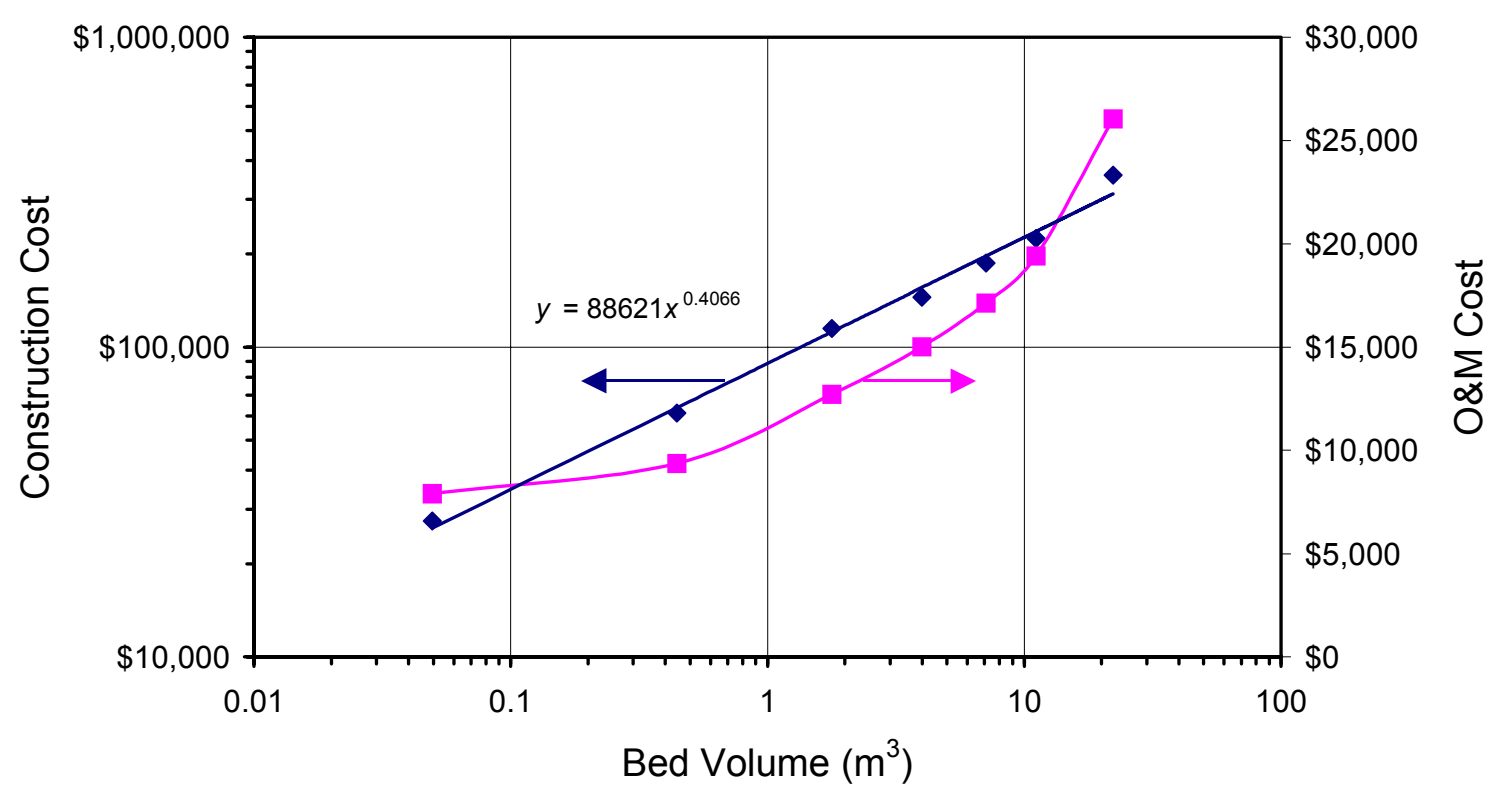

Fig. 21. Construction and O\&M costs for pressure GAC systems.

Since most adsorption systems use two columns in series, another estimate was prepared based on data for ion-exchange systems, constructed with the total bed volume divided into two equal-size columns. The 1998 construction cost for such system is shown in Fig. 23. ${ }^{16}$ 


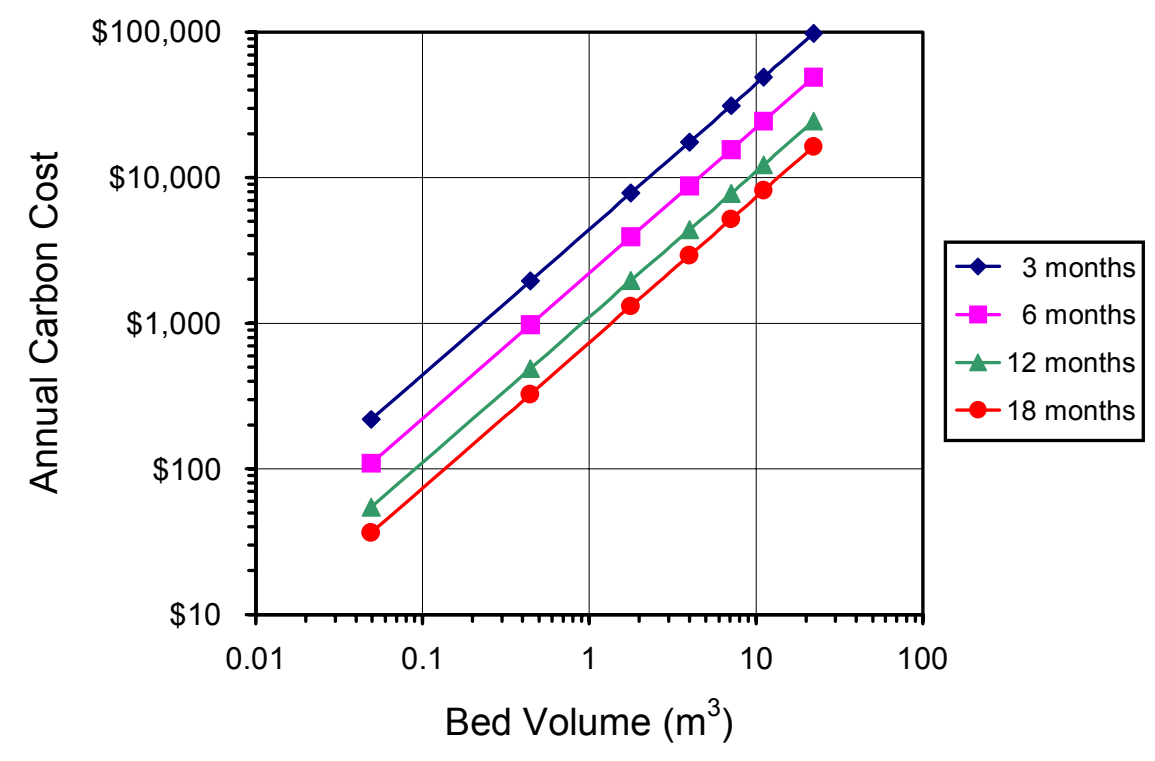

Fig. 22. Cost for replacement of carbon at different intervals. Carbon cost was estimated at $\$ 1.20 / \mathrm{lb}$, installed.

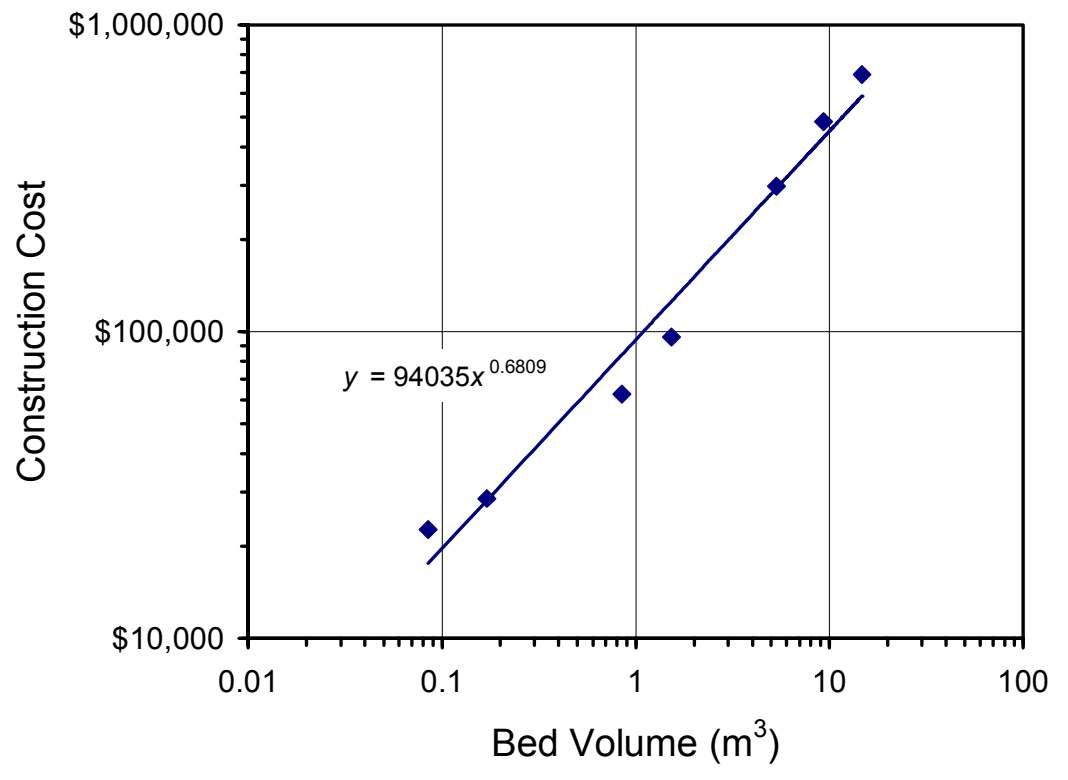

Fig. 23. Construction cost of two-column system with a sorbent cost of $\$ 1000 / \mathrm{ft}^{3}$.

If the target removal efficiencies can be reached with either a carbon- or a sorbent-based system, the properties of the sorbent-based system must offset the higher cost of the sorbent. Figure 24 illustrates the effect of construction cost on alternative treatments. In this figure, the construction cost has been plotted as a function of processing flow rate through each of the columns. The base case is a GAC system 
treating water at $1 \mathrm{~m}^{3} / \mathrm{min}$ with a processing rate of $0.1 \mathrm{BV} / \mathrm{min}$ through each column. The construction cost for such a system, including an initial charge of carbon, is about $\$ 197,000$. The other cases represent a sorption system with a specialized resin treating water at $1 \mathrm{~m}^{3} / \mathrm{min}$ at various processing flow rates and with different sorbent costs. As noted, a system with a sorbent cost of $\$ 1000 / \mathrm{ft}^{3}$ would have to operate at a processing flow rate of $0.67 \mathrm{BV} / \mathrm{min}$ or higher to cost the same as the GAC system. A system with a sorbent cost of $\$ 400 / \mathrm{ft}^{3}$ would have to operate at a processing rate of $0.32 \mathrm{BV} / \mathrm{min}$ or higher to cost the same as the GAC system. The annual cost for replacement of the sorbent is directly proportional to the cost of the sorbent and the replacement frequency. The replacement frequency depends on the sorptive capacity. A sorbent costing $\$ 400 / \mathrm{ft}^{3}$ would have to have the have a sorptive capacity of about 10 times that of carbon (at $\$ 42 / \mathrm{ft}^{3}$ ) to have the same annual cost.

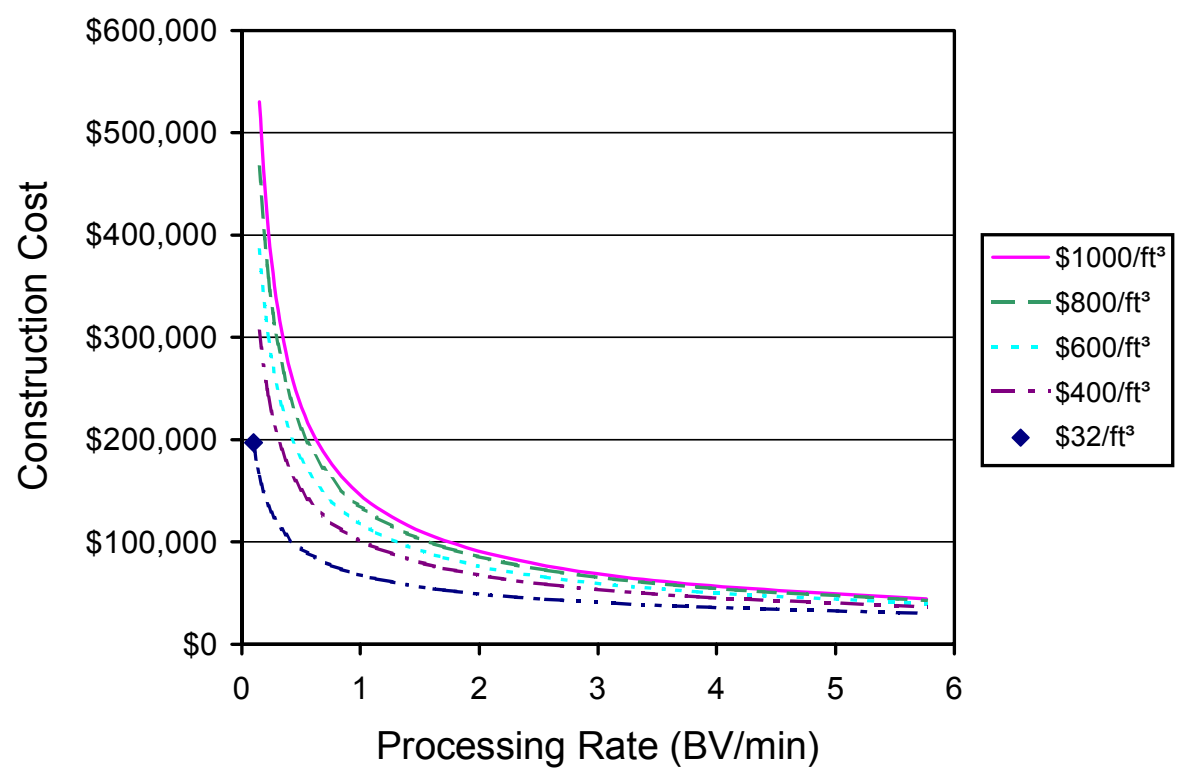

Fig. 24. Construction cost as a function of processing flow rate and sorbent cost. The base case (indicted by a diamond) is a GAC system operating at $0.1 \mathrm{BV} / \mathrm{min}$.

\section{CONCLUSIONS}

In conclusion, the thiol-based resins gave the best performance when removing low concentrations of mercury in water at two DOE facilities in field experiments. It was difficult to achieve the targeted low nanogram-per-liter levels at both sites; however the resins removed a substantial amount of mercury. This is attributed to the mercury speciation, since filtration tests have shown that a significant portion of the mercury at each test location is particle bound or associated with particulate and colloidal matter. Due 
to the scattering of data, mathematical modeling was limited to predict the behavior of active mercury. Since the field samples contained a substantial amount of particle-bound mercury, the mathematical models did not represent the field data very well. Nevertheless, it was useful to predict the performance of these sorbents at very low concentrations of mercury.

The engineered SAMMS material proved to be as effective in removing mercury at the NRWTP as the best of the other sorbents. The material performed almost as well as some of the best sorbents at the UEFPC. The best performing sorbents were SAMMS; Keyle:X, by SolmeteX, Inc.; and SIR-200, by ResinTech, Inc. It was also found that the Keyle:X performed better at the NRWTP when the water was pretreated with hypochlorite to oxidize some mercury species.

Mathematical modeling was also used to investigate the possible wall effects in the small-scale studies. Based on a theoretical derivation of relationships for wall effects, supported by the field data, it was concluded that wall effects played a very minor role in the experiments. The most important factor that governed the performance of the sorbents at high flow rates was the diffusion of mercury inside the sorbent. It was found that the values for the effective diffusivities were quite high, possibly due to blockage of macro pores by the particulates.

Estimation of construction costs for treatment systems indicated that the specialized sorbents would have to operate at flow rates 3 to 6 times higher than that of a comparable GAC system in order to have the same construction cost. The sorptive capacity of the specialized sorbents would need to be substantially higher than that of the GAC. 


\section{NOMENCLATURE}

$$
\begin{aligned}
& C=\text { liquid mercury concentration in the bulk liquid }\left(\mathrm{mol} / \mathrm{m}^{3}\right) \\
& C_{s}=\text { liquid mercury concentration at the sorbent surface }\left(\mathrm{mol} / \mathrm{m}^{3}\right) \\
& C_{\text {in }}, C_{\text {out }}=\text { liquid mercury concentration at column inlet, outlet }\left(\mathrm{mol} / \mathrm{m}^{3}\right) \\
& d \quad=\text { sorbent particle diameter }(\mathrm{m}) \\
& D \quad=\text { column diameter }(\mathrm{m}) \\
& D_{\text {eff }} \quad=\text { effective mercury diffusivity in the sorbent }\left(\mathrm{m}^{2} / \mathrm{s}\right) \\
& D_{f} \quad=\text { mercury diffusivity in fluid }\left(\mathrm{m}^{2} / \mathrm{s}\right) \\
& {[\mathrm{Hg}]=\text { mercury concentration in isotherm studies }\left(\mathrm{g} / \mathrm{m}^{3}\right)} \\
& k_{f} \quad=\text { fluid-phase mass transfer coefficient }(1 / \mathrm{s}) \\
& \text { (It should be noted that } k_{f} a_{p} \text { and } k_{f} a \text { are used interchangeably with } k_{f} \text { in some references) } \\
& k_{p} \quad=\text { solid phase mass transfer coefficient }(1 / \mathrm{s}) \\
& K=\text { linear isotherm constant }\left(\mathrm{m}^{3} \text { liquid } / \mathrm{m}^{3} \text { solids }\right) \\
& K_{D} \quad=\text { linear isotherm constant, } K(1-\varepsilon) / \rho_{s}\left(\mathrm{~m}^{3} \text { liquid } / \mathrm{kg} \text { solids }\right) \\
& L=\text { liquid volume in isotherm studies }\left(\mathrm{m}^{3}\right) \\
& \Delta p \quad=\text { pressure drop in sorbent column }(\mathrm{Pa}) \\
& \bar{q} \quad=\text { average mercury concentration in the sorbent }\left(\mathrm{mol} / \mathrm{m}^{3}\right) \\
& q_{s}=\text { mercury concentration in the sorbent at the surface }\left(\mathrm{mol} / \mathrm{m}^{3}\right) \\
& t \quad=\text { time (s) } \\
& W \quad=\text { dry sorbent weight in isotherm studies }(\mathrm{kg}) \\
& z, Z \quad=\text { distance from inlet, length of bed (m) } \\
& \varepsilon, \varepsilon_{\min }=\text { void fraction, miminum void fraction in bed }\left(\mathrm{m}^{3} / \mathrm{m}^{3}\right) \\
& \bar{\varepsilon}_{s} \quad=\text { average void fraction in bed close to the column wall }\left(\mathrm{m}^{3} / \mathrm{m}^{3}\right) \\
& \varepsilon_{c}=\text { void fraction in core of the bed }\left(\mathrm{m}^{3} / \mathrm{m}^{3}\right) \\
& \mu \quad=\text { absolute viscosity for fluid (Pa s) } \\
& v \quad=\text { interstitial fluid velocity }(\mathrm{m} / \mathrm{s}) \\
& v_{s} \quad=\text { empty-bed superficial velocity, } v \varepsilon(\mathrm{m} / \mathrm{s}) \\
& v_{s, c}=\text { bed superficial velocity in the core of the column }(\mathrm{m} / \mathrm{s}) \\
& \bar{v}_{s, s} \quad=\text { average bed superficial velocity at the column wall }(\mathrm{m} / \mathrm{s}) \\
& \rho_{s} \quad=\text { bulk density of the sorbent }\left(\mathrm{kg} / \mathrm{m}^{3}\right) \\
& \rho_{f} \quad=\text { fluid-phase density }\left(\mathrm{kg} / \mathrm{m}^{3}\right) \\
& \operatorname{Re} \quad=\text { Reynolds number, } \rho_{f} v_{s} d / \mu \\
& \text { Sc } \quad=\text { Schmidt number, } \mu /\left(\rho_{f} D_{f}\right)
\end{aligned}
$$




\section{ACKNOWLEDGMENTS}

Funding for this work was provided by the DOE Mixed Waste Focus Area and by local waste management and environmental restoration organizations. ORNL is managed by Lockheed Martin Energy Research Corp. for the U.S. Department of Energy under contract DE-AC05-96OR22464. Part of this work was performed in collaboration with Alabama A\&M University (Drs. W. Hollerman and D. Holland at the Center for Irradiation of Materials) and TN \& Associates, Inc. (Oak Ridge, TN). Special thanks are extended to the following for supporting this project: Dr. Jack Collins, of ORNL, who constructed the engineered form of the SAMMS material; Dr. Xiangdong Feng, of PNNL, who provided the SAMMS material for this study; and to Janice Hensley, with the Reduction of Mercury from Plant Effluent Program at the Oak Ridge Y-12 Plant.

\section{REFERENCES}

1. J. Hensley, Oak Ridge Y-12 Plant, personal communication (concerning samples collected February 12, 1997), June 1997.

2. X. Feng et al., Self-Assembled Mercaptan on Mesoporous Silica (SAMMS) Technology for Mercury Removal and Stabilization, PNNL-11691, Pacific Northwest National Laboratory, Richland, Wash., September 1997.

3. P. A. Taylor, K. T. Klasson, S. L. Corder, T. R. Carlson, and K. R. McCandless, Mercury Separation from Mixed Waste: Annual Report, ORNL/TM-13121, Oak Ridge National Laboratory, Oak Ridge, Tenn., November 1995.

4. Mercury Treatability Study Final Report, Oak Ridge Y-12 Plant, BJC/OR-46, Bechtel Jacobs Company LLC, Oak Ridge, Tenn., June 1998.

5. D. A. Bostick and T. K. Klasson, Multi-Weight Isotherm Results for Mercury Removal in Upper East Fork Poplar Creek Water, ORNL/TM-13582, Oak Ridge National Laboratory, Oak Ridge, Tenn., February 1998.

6. P. A. Taylor and K. T. Klasson, Results of Small-Scale Tests for Removing Mercury from ORNL Process Wastewater, ORNL/TM-13763, Oak Ridge National Laboratory, TN, June 1999.

7. Method 1631: Mercury in Water by Oxidation, Purge and Trap, and Cold Vapor Atomic Fluorescence, EPA 821-R-96-012, U.S. Environmental Protection Agency, Office of Water, Washington, D.C., 1996;

8. Y. Kawamura et al., Water Sci. Technol. 35, 97-105 (1997). 
9. D. M. Ruthven, Principles of Adsorption and Adsorption Processes, John Wiley \& Sons, New York, 1984, pp. 235-243.

10. J. B. Rosen, Ind. Eng. Chem. 46(8), 1590-1594 (1954).

11. D. M. Ruthven, Principles of Adsorption and Adsorption Processes, John Wiley \& Sons, New York, 1984, pp. 214-215.

12. Perry's Chemical Engineers' Handbook, eds. R. H. Perry and D. W. Green, McGraw-Hill, New York, 1984, pp. 16-22.

13. H. Martin, Chem. Eng. Sci. 33, 913-919 (1978).

14. S. Ergun, Chem. Eng. Prog. 48, 89 (1952).

15. Perry's Chemical Engineers' Handbook, eds. R. H. Perry and D. W. Green, McGraw-Hill, New York, 1984, pp. 16-23.

16. R. C. Gumerman, B. E. Burris, and S. P. Hansen, Small Water System Treatment Cost, Pollution Technology Review No. 136, Noyes Data Corp., Park Ridge, N.J., 1986. 

Appendix

DETAILS OF RESULTS FROM BATCH EXPERIMENTS 

Table A-1. Multiweight sorption isotherm results for SIR-200, by Resin Tech, Inc.

\begin{tabular}{llccc}
\hline Sample bottle & $\begin{array}{c}\text { Dry sorbent } \\
\text { weight }{ }^{2}, W_{i} \\
(\mathrm{~g})\end{array}$ & $\begin{array}{c}\text { Liquid volume, } L_{i} \\
(\mathrm{~mL})\end{array}$ & $\begin{array}{c}\text { Mercury spike, [Hg] spike } \\
(\mathrm{ng} / \mathrm{L})\end{array}$ & $\begin{array}{c}\text { Equilibrium } \\
\text { concentration, }[\mathrm{Hg}]_{i} \\
(\mathrm{ng} / \mathrm{L})\end{array}$ \\
\hline SIR-1B & 0.1754 & 144.63 & 86013 & 900.0 \\
SIR-2B & 0.3891 & 146.43 & 84955 & 746.0 \\
SIR-3B & 0.3744 & 160.57 & 77474 & 1002.0 \\
SIR-4B & 0.3674 & 150.52 & 328926 & 1019.0 \\
SIR-5B & 2.0587 & 152.20 & 81735 & 22.6 \\
SIR-6B & 3.6544 & 150.40 & 82713 & 18.0 \\
SIR-7B & 0.0 & 150.73 & 82532 & 60723.0 \\
SIR-8A & 0.0 & 149.32 & 0.0 & 644.0 \\
SIR-9B & 0.1078 & 189.60 & 0.0 & 14.3 \\
SIR-10B & 0.2036 & 154.53 & 0.0 & 9.5 \\
SIR-11B & 0.3910 & 156.77 & 0.0 & 1.8 \\
\hline
\end{tabular}

${ }^{a}$ Sorbent moisture content was $18.8 \%$. 



\section{INTERNAL DISTRIBUTION}

1-2. D. A. Bostick

3. T. B. Conley

4. B. H. Davison

5. L. L. Farr

6. J. F. Hensley

7. D. A. Hutchins

8. R. T. Jubin
9. J. M. Japp

10-11. K. T. Klasson

12. D. R. McTaggart

13-14. P. A. Taylor

15. Central Research Library

16. Laboratory Records, RC

17. Laboratory Records, for OSTI

\section{EXTERNAL DISTRIBUTION}

18. C. H. Brown, ADA Technologies, Inc., 8100 Shaffer Parkway Suite \#130, Litteton, CO 80127

19. Becky Sams, Lockwood Greene Technologies, 125 Broadway, Oak Ridge, TN 37830

20. M. J. Connolly, Lockheed Martin Idaho Technologies Company, P.O. Box 1625, Idaho Falls, ID 83415-3875

21. G. A. Hulet, Lockheed Martin Idaho Technologies Company, P.O. Box 1625, Idaho Falls, ID 83415-3875

22. W. A. Owca, U.S. Department of Energy, MS-1225, 850 Energy Drive, Idaho Falls, ID 83401-1563 